\title{
Adaptive Acceleration of Visually Evoked Smooth Eye Movements in Mice
}

\author{
- Takashi Kodama and Sascha du Lac \\ Department of Otolaryngology-Head and Neck Surgery, The Johns Hopkins University School of Medicine, Baltimore, Maryland 21205
}

The optokinetic response (OKR) consists of smooth eye movements following global motion of the visual surround, which suppress image slip on the retina for visual acuity. The effective performance of the $0 \mathrm{KR}$ is limited to rather slow and low-frequency visual stimuli, although it can be adaptably improved by cerebellum-dependent mechanisms. To better understand circuit mechanisms constraining OKR performance, we monitored how distinct kinematic features of the OKR change over the course of OKR adaptation, and found that eye acceleration at stimulus onset primarily limited OKR performance but could be dramatically potentiated by visual experience. Eye acceleration in the temporal-to-nasal direction depended more on the ipsilateral floccular complex of the cerebellum than did that in the nasal-to-temporal direction. Gaze-holding following the OKR was also modified in parallel with eye-acceleration potentiation. Optogenetic manipulation revealed that synchronous excitation and inhibition of floccular complex Purkinje cells could effectively accelerate eye movements in the nasotemporal and temporonasal directions, respectively. These results collectively delineate multiple motor pathways subserving distinct aspects of the OKR in mice and constrain hypotheses regarding cellular mechanisms of the cerebellumdependent tuning of movement acceleration.

Key words: adaptation; cerebellum; mouse; optokinetic response

\section{Significance Statement}

Although visually evoked smooth eye movements, known as the optokinetic response (OKR), have been studied in various species for decades, circuit mechanisms of oculomotor control and adaptation remain elusive. In the present study, we assessed kinematics of the mouse OKR through the course of adaptation training. Our analyses revealed that eye acceleration at visual-stimulus onset primarily limited working velocity and frequency range of the OKR, yet could be dramatically potentiated during OKR adaptation. Potentiation of eye acceleration exhibited different properties between the nasotemporal and temporonasal OKRs, indicating distinct visuomotor circuits underlying the two. Lesions and optogenetic manipulation of the cerebellum provide constraints on neural circuits mediating visually driven eye acceleration and its adaptation.

\section{Introduction}

Motor neurons can change their firing rates instantaneously and robustly to rapidly initiate or accelerate movements. While the same pool of motor neurons drive all eye movements, different types of eye movements exhibit different acceleration capabilities. The saccade, the fastest eye movement for rapid gaze shifts, can accelerate eyes at $>20,000^{\circ} \mathrm{s}^{2}$, attaining $>400 \%$ s of eye ve-

\footnotetext{
Received Jan. 7, 2016; revised April 19, 2016; accepted May 17, 2016.

Author contributions: T.K. and S.d.L. designed research; T.K. performed research; T.K. contributed unpublished reagents/analytic tools; T.K. analyzed data; T.K. and S.d.L. wrote the paper.

This work was supported by National Institutes of Health Grant EY11027. We thank H. Fujita for valuable discussions.

The authors declare no competing financial interests.

Correspondence should be addressed to either Takashi Kodama or Sascha du Lac, Department of Otolaryngology-

Head and Neck Surgery, The Johns Hopkins University School of Medicine, Ross Research Building 420, 720 Rutland Avenue, Baltimore, MD 21205.E-mail: takashi@jhmi.edu or sascha@jhmi.edu.

DOI:10.1523/JNEUROSCI.0067-16.2016

Copyright $\odot 2016$ the authors $\quad 0270-6474 / 16 / 366836-14 \$ 15.00 / 0$
}

locity in tens of milliseconds (Leigh and Zee, 2006). The vestibulo-ocular reflex (VOR), which counter-rotates the eyes for gaze stabilization as the head moves, also shows excellent eye acceleration ( $>2000^{\circ} / \mathrm{s}^{2}$; Halmagyi et al., 1990), preventing image blur on the retina during fast and high-frequency head movements. In contrast, the optokinetic response (OKR), an eye movement following global motion of visual surrounding, works with a limited eye-acceleration capability $\left(<100^{\circ} / \mathrm{s}^{2}\right.$ in rats; Harvey et al., 1997; for rabbits, see Collewijn, 1969), suppressing only slow and low-frequency image slip on the retina. These different types of eye movements are controlled via distinct premotor pathways. The limited eye acceleration in the OKR indicates that the premotor pathway for the OKR is less effective in instantaneous modulation of motor neuron firing than those for the saccade and VOR.

What constrains the acceleration capability of the OKR premotor pathway? Historical work with rabbits led to the prevailing view that the OKR is primarily initiated by ON-type direction- 
selective ganglion cells (ON-DSGCs) in the retina (for review, see Simpson, 1984; Schiller, 2010), which preferentially respond to relatively slow visual stimulation $(\sim 3 \%$ in mice; Dhande et al., 2013). For fast visual stimulation, which calls for high eye acceleration, ON-DSGCs send rather attenuated signals to downstream neurons, potentially limiting eye acceleration. It has been reported, however, that the OKR can adaptively improve its performance to fast and high-frequency visual stimulation (Collewijn and Grootendorst, 1979; Nagao, 1983; Marsh and Baker, 1997), implying that eye-acceleration capability may have room for potentiation. Previous studies demonstrated that OKR adaptation requires intact function of the cerebellum; in particular, the flocculus and ventral paraflocculus (herein referred to as the floccular complex; Nagao, 1983; Katoh et al., 1998; Shutoh et al., 2006; Endo et al., 2009; Okamoto et al., 2011; Wada et al., 2014). Given the direct innervation of Purkinje cells (PCs) in the floccular complex onto brainstem premotor neurons that drive the OKR, it is likely that cellular constraints of eye-acceleration capability reside in the motor side of the OKR pathway.

To investigate whether and how the cerebellar PCs and downstream premotor neurons control and potentiate eyeacceleration capability, and to pave the way for further cellular analyses using modern molecular tools and genetics, we examined changes in eye acceleration in mouse OKRs over the course of OKR adaptation. To isolate the eye-acceleration component of the OKR, we used a brief constant-velocity visual stimulation ( $\leq 1 \mathrm{~s}$; Tabata et al., 2010) to evoke the OKR, which also allowed us at the same time to monitor changes in other kinematic features, such as eye deceleration and gaze-holding (van Alphen et al., 2001). We first characterized kinematic features of mouse OKRs for comparison with other species. Subsequently, we monitored changes in the kinematics features over the course of the OKR adaptation training and examined eye-acceleration capability of the floccular complex PCs using optogenetic excitation and inhibition.

\section{Materials and Methods}

Mouse lines. C57BL /6J mice were purchased from the Jackson Laboratory. The Pcp2-Cre;Ai27 and Pcp2-Cre;Ai40 lines were generated by crossing a Pcp2-Cre line (Barski et al., 2000; \#004146, Jackson Laboratory) with Ai27 (Madisen et al., 2012; \#012567, Jackson Laboratory) and Ai40 lines (\#021188, Jackson Laboratory), respectively. For OKR kinematics characterization, OKR adaptation, and flocculectomy, male 2-4month-old C57BL/6J mice were used. For optogenetic stimulation of PCs, both male and female 2-8-month-old mice were used. All the experimental protocols for this study were approved by institute animal care and use committees.

Implant of headpost and optical fiber. An acrylic headpost was implanted onto the skull under isoflurane anesthesia as described previously (Faulstich et al., 2004). For optogenetic excitation, a fiber optic implant (200 $\mu \mathrm{m}$ core diameter, $6 \mathrm{~mm}$ fiber length; Doric Lenses) was guided toward the left floccular complex by monitoring photoevoked eye movements, and cemented by dental acrylic. Mice were allowed to recover for $\geq 3 \mathrm{~d}$ before the first eye-movement recordings.

Eye-movement recordings and visual and optogenetic stimulation. Methods for mouse eye-movement recording were described by Stahl et al. (2000) and Faulstich et al. (2004). Briefly, mice with headposts were restrained in a custom-built animal holder on a turntable surrounded by an optokinetic drum displaying a vertical black-and-white stripe pattern (stripe width, $5^{\circ}$ visual angle). A miniature infrared video camera fixed on the turntable recorded eye movements at a scan rate of $200 \mathrm{~Hz}$. The movements of the pupil in the $2 \mathrm{D}$ video image were transformed into eye position (unit, degree) using the video-oculography method described by Stahl et al. (2000). An eye drop of physostigmine salicylate (0.05-
$0.125 \%$ ) was used to limit pupil dilation in all the eye-movement recordings. We observed no interfering effect of physostigmine to the OKR.

For visual stimulation of constant velocity, the optokinetic drum was rotated at a constant velocity in the dark, then illuminated using a white LED (Cree XLamp XR-E cool white) for specific durations. The switching of the illumination was accomplished in $<200 \mu \mathrm{s}$. The drum position followed a triangular waveform so that the direction of visual stimulation alternated. The interstimulus intervals were 2.5 and $3.5 \mathrm{~s}$ for stimulation of $<1$ and $1 \mathrm{~s}$, respectively. The OKR in each direction was recorded 20-30 times. Visual stimuli were presented binocularly in all of the experiments.

Stimulation light for both optogenetic excitation and inhibition was generated using a blue LED (Cree XLamp XR-E blue; peak at $460 \mathrm{~nm}$ ). For optogenetic excitation, stimulation light was delivered to floccular complex PCs via implanted optical fiber $\left(46.3 \mathrm{~mW} / \mathrm{mm}^{2}\right.$ at the fiber tip). For optogenetic inhibition, a small incision $(\sim 2 \mathrm{~mm})$ was made on the scalp over the left temporal bone under isoflurane anesthesia. Then, under local anesthesia by lidocaine, an optical fiber (core diameter, 910 $\mu \mathrm{m}$; Thorlabs; $183.8 \mathrm{~mW} / \mathrm{mm}^{2}$ at the fiber tip) for photostimulation was placed through the incision onto muscles covering the left temporal bone. Before starting recording, the OKR and VOR were checked to confirm wakefulness of animals.

Photostimulation of $0.5 \mathrm{~s}$ and $1 \mathrm{~ms}$ was applied every 5 and $1 \mathrm{~s}$ for $10-30$ and 50 times, respectively, always in the dark. Stimulation and recording were controlled by custom-written software in LabVIEW (National Instruments).

OKR adaptation training. The training paradigm is described in Figure $2 A$. In the training under the free-moving condition, one or two mice were placed in a transparent mouse cage (width, $18.5 \mathrm{~cm}$; depth, $30 \mathrm{~cm}$; height, $13 \mathrm{~cm}$; MicroVent system caging, Allentown), the top of which was covered by a clear film (3M Highland 903). Normal bedding material (made from corn cobs) was placed on the floor of the cage to ease each animal's stress. For bidirectional OKR adaptation, sinusoidal visual stimulation $(0.5 \mathrm{~Hz} \pm 15.7 \%$ s $)$ was used as training stimulation. For unidirectional OKR adaptation, the velocity of an optokinetic drum was sinusoidally modulated between 0 and $31.4 \%$ at $0.5 \mathrm{~Hz}$, as shown in Figure $4 A$. Half of the mice were trained in the clockwise direction and the other half in the counterclockwise direction. There was no difference in training performance between the two training directions, and results were pooled. Mice were actively moving in the cage almost the entire period of the training. For the training under the head-fixed condition, a mouse was placed in the animal holder in the exact same way as for eye-movement recording, and subjected to the training stimulation.

Flocculectomy. Under isoflurane anesthesia, the left temporal bone was exposed rostral to the posterior semicircular canal and dorsal to the horizontal canal. Then, a small craniotomy ( $\sim 700 \mu \mathrm{m}$ in diameter) was made in the bony plate overlaying the paraflocculus. Great care was taken not to damage the semicircular canals. Through the craniotomy, the floccular complex was aspirated with a blunt 22 gauge needle. Then, the incision was carefully sutured. The OKR was recorded $2 \mathrm{~d}$ after the surgery. After the recording, mice were transcardially perfused with $0.1 \mathrm{M}$ PBS, followed by $4 \%$ paraformaldehyde in PBS, under deep anesthesia by avertin $(500 \mathrm{mg} / \mathrm{kg}$ of body weight). The brains were sectioned $(50 \mu \mathrm{m})$ and stained by Nissl for histological confirmation of the lesion.

Extracellular recording. Under ketamine $(50 \mathrm{mg} / \mathrm{kg}) / x y l a z i n e ~(8 \mathrm{mg} /$ $\mathrm{kg}$ ) anesthesia, a glass electrode filled with $2 \%$ pontamine sky blue in 0.5 M sodium acetate $(5 \sim 12 \mathrm{M} \Omega)$ was inserted through a craniotomy made on the interparietal bone or the temporal bone overlaying the paraflocculus in the same way as for flocculectomy. PCs were identified by the presence of complex spikes. Photoevoked responses were indistinguishable between PCs recorded in the flocculus $(n=47)$ versus the paraflocculus $(n=31)$, which were combined for the analyses. Spike sorting and data analyses were done with codes written in Igor Pro (Wavemetrics). Values are shown as mean \pm SEM.

Eye-movement data analyses. Eye position measured by the videooculography (Stahl et al., 2000) was used as raw data in all the eyemovement analyses, where $0^{\circ}$ corresponded to the center of the eye orbit (i.e., the resting eye position). We first manually inspected traces of eye position and its derivative, eye velocity, to identify and mask recording 
periods containing successive saccades. Then we subjected the traces to an automatic noise-removal process, which excluded from the following analyses sporadic saccades (defined as eye movements of $>200 \%$ ) and periods of poor eye-tracking detected as sudden moves of corneal reflection of reference infrared LED $(>10 \mathrm{~mm} / \mathrm{s})$. A period of $>500 \mathrm{~ms}$ was excluded for each noise detected. To compute stimulus-triggered average of eye position, stimulus-triggered average of eye velocity was first computed from derivative of raw eye position ("raw eye velocity"), and then integrated. The traces were offset so that the average eye position at the stimulus onset was $0^{\circ}$. This method effectively isolated eye-position changes by stimulus from those by saccades and slow centripetal eye drift, without compromising temporal resolution. For analyses of eye-velocity profiles, low-pass-filtered stimulus-triggered average of eye velocity was computed by differentiating low-pass-filtered eye-position traces [finite impulse response (FIR) filter: the end of the pass band, $1 \mathrm{~Hz}$; start of the reject band, $10 \mathrm{~Hz}$; number of filter coefficients, 101, corresponding to $500 \mathrm{~ms}$ ] and subsequent stimulus-triggered averaging. The low-pass filter attenuated high frequency noise produced by differentiation but compromised temporal resolution at eye movement onset. The central difference method was used for all the differentiation processes.

In rare cases ( 4 of 418 cases), an unidirectional eye-position drift was discernible in stimulus-triggered average of eye position. In such cases, the unidirectional drift was removed by offsetting the raw eye-velocity trace so that the average eye velocity for the entire recording period became $0 \%$. Then the stimulus-triggered average of eye position was computed. Note that neither OKR adaptation training, flocculectomy, nor PC-specific optogenetic stimulation caused such a unidirectional eye drift.

Onset latency was manually measured using stimulus-triggered average of eye position, which had the best temporal resolution and signal-to-noise ratio that we could attain. Eye-movement onset was defined as the first time point after the stimulus onset from which eye position monotonically changed toward the direction of the visual stimulation for $\geq 50 \mathrm{~ms}$. Note that a transport delay in the videooculography system (delay between actual and detected movements of pupil/corneal reflection) is estimated as $2.05-3.75 \mathrm{~ms}$, which limits temporal accuracy of the eye-movement analyses. When average eye position and velocity at specific timings from stimulus onset was measured, an average between the timing and $50 \mathrm{~ms}$ before was used for measurement robustness. The time constant of eye deceleration at stimulus offset (deceleration $\tau$ ) was obtained by fitting a single exponential curve to the stimulus-triggered average of eye velocity, from stimulus offset to $2 \mathrm{~s}$ later. Traces that showed poor fitting to the exponential function were manually identified and excluded from the analyses ( 8 of 292 cases). Deceleration $\tau$ was not estimated from the OKRs of small velocity change (i.e., those evoked by $5 \%$ s stimulation) due to unreliable fitting. For flocculectomized animals, regression analysis for deceleration $\tau$ was performed with the average of stimulus-triggered averages of eye velocity across animals. This method was necessary because the average traces from individual animals produced rather low velocity peaks and low signal-to-noise ratio (Fig. $6 B$ ). The poststimulus eye movements toward the direction opposite the stimulation (rebounding gaze drift) was measured by integrating poststimulus eye velocity in the direction opposite that of the stimulation for $2 \mathrm{~s}$, using low-pass-filtered stimulus-triggered average of eye velocity.

To compute eye-velocity amplitude and phase of the sinusoidal OKR and VOR, a sinusoidal curve was fitted to an eye-velocity trace, which was generated by differentiating a low-pass-filtered eye-position trace (the same FIR filter already described). Noise was removed before the fitting analysis, as already described. Frequency of fitting the sinusoidal curve was fixed to that of the stimulation. Acceleration amplitude of the sinusoidal OKR was analytically calculated as $2 \pi * f * A$, where $f$ and $A$ are stimulation frequency and eye-velocity amplitude, respectively. Eye acceleration $(y)$ plotted against stimulus acceleration $(x)$ was fitted with an exponential function $y=\alpha *[1-\exp (-x / \tau)]$, where $\alpha$ and $\tau$ were used as estimation of maximum and dynamic range of eye acceleration, respectively.

All data analyses were done using Igor Pro. Values are shown as mean \pm SEM.
Statistical tests. To test whether the direction, duration, and velocity of visual stimulation significantly affected OKR kinematic features (Fig. $1 E-G, I-K)$, two-way ANOVA was used. Statistical significance of the OKR adaptation training effect and flocculectomy was tested by paired $t$ test (Figs. $2 C, D, 3 C-F, 4 D-G, 6 C-G$ ). Statistical significance of directionspecific adaptation time courses was tested by two-way ANOVA (Fig. $5 C-E$ ). Difference in eye movements evoked by PC photoexcitation between the ipsilateral and contralateral eyes was tested by paired $t$ test when both eyes were measured from an identical group of mice, and by unpaired $t$ test when the eyes were recorded from different groups of mice. In case of multiple comparison, $p$ values were adjusted using the Benjamini-Hochberg's false discovery rate. $\mathrm{R}$ (www.r-project.org) was used for all the statistical tests. In all the figures, ${ }^{\star} p<0.05,{ }^{\star *} p<0.01$, ${ }^{* * *} p<0.001$.

\section{Results}

\section{Five kinematic features in the mouse OKR}

The OKR evoked by binocular visual stimuli in mice showed characteristic kinematic features comparable to those reported in other species, including humans, but with considerable quantitative differences. In response to the constant-velocity stimulation of $1 \mathrm{~s}$ (Fig. $1 A-C$ ), the OKR was initiated after an onset latency (Fig. $1 D, E$ ), which was independent from stimulation velocity and the direction of the OKR when stimulation velocity was $>15^{\circ} / \mathrm{s}$ ( $p=0.11$ and 0.49 , respectively). Significantly longer latency was observed at stimulation of $5 \% \mathrm{~s}\left(5^{\circ} \mathrm{s}, 110.7 \pm 7.5 \mathrm{~ms}\right.$; $15-90 \%$ s, $81.4 \pm 1.9 \mathrm{~ms}, n=7$ mice, $p<0.05$ in paired $t$ test, including both directions).

After the onset latency, the eye velocity rapidly increased until $\sim 0.2$ s after stimulus onset, representing eye acceleration (Fig. $1 B, C)$. The OKR in the temporal-to-nasal direction (T-N OKR) attained higher velocity than the OKR in the nasal-to-temporal direction (N-T OKR) over the range of stimulation velocities tested $(p<0.001$; Fig. $1 F)$. The asymmetry between the N-T and $\mathrm{T}-\mathrm{N}$ OKRs has been observed in lateral-eyed mammals that do not possess the fovea in the retina, in particular in response to monocular visual stimulation (rabbits: Collewijn, 1969; rats: Harvey et al., 1997). The onset velocity peak in mice (measured at $0.2 \mathrm{~s}$ after stimulus onset) was greater than that in rabbits $(<1 \%$; Collewijn, 1969), comparable to that in rats $(\sim 10 \%$ s; Harvey et al., 1997), but smaller than that in monkeys ( $>50^{\circ} / \mathrm{s}$; Cohen et al., 1977). Note that in foveate animals, such as monkeys, eye acceleration at stimulus onset is driven not only by the OKR, but also by the ocular following response, which engages cerebral cortical mechanisms (Takemura et al., 2007). The onset velocity peak reached maximum at 30 and $15 \%$ of the stimulation for the T-N $\left(12.1 \pm 1.0^{\circ} / \mathrm{s}, n=7\right.$ mice $)$ and the $\mathrm{N}-\mathrm{T}$ OKRs $\left(7.9 \pm 0.5^{\circ} / \mathrm{s}, n=\right.$ 7 mice), respectively, whereas the maximal gain (eye velocity divided by stimulation velocity) was attained at the lowest stimulation velocity tested $(5 \%$ s: $0.70 \pm 0.08$ for the N-T OKR, $0.94 \pm$ 0.09 for the T-N OKR).

After eye acceleration at stimulus onset, the eye velocity was maintained or even gradually decreased during stimulation (Fig. $1 B, C)$, which is in contrast to the buildup of eye velocity during the stimulation reported in other species (rats: Hess et al., 1985; rabbits: Collewijn, 1969; monkeys: Cohen et al., 1977; humans: Fletcher et al., 1990). The T-N OKR showed greater velocity decrease than the N-T OKR (Fig. $1 G ; p<0.01$ ). This poor or absent velocity buildup may partly account for the cessation of eye movements even during the stimulation, when the duration of the stimulation was long (e.g., 20 s; Fig. $1 H$ ). The OKR evoked by prolonged visual stimulation was highly variable across trials and animals, as previously reported (Beraneck and Cullen, 2007).

After the end of the $1 \mathrm{~s}$ stimulation, the eye velocity instanta- 
A
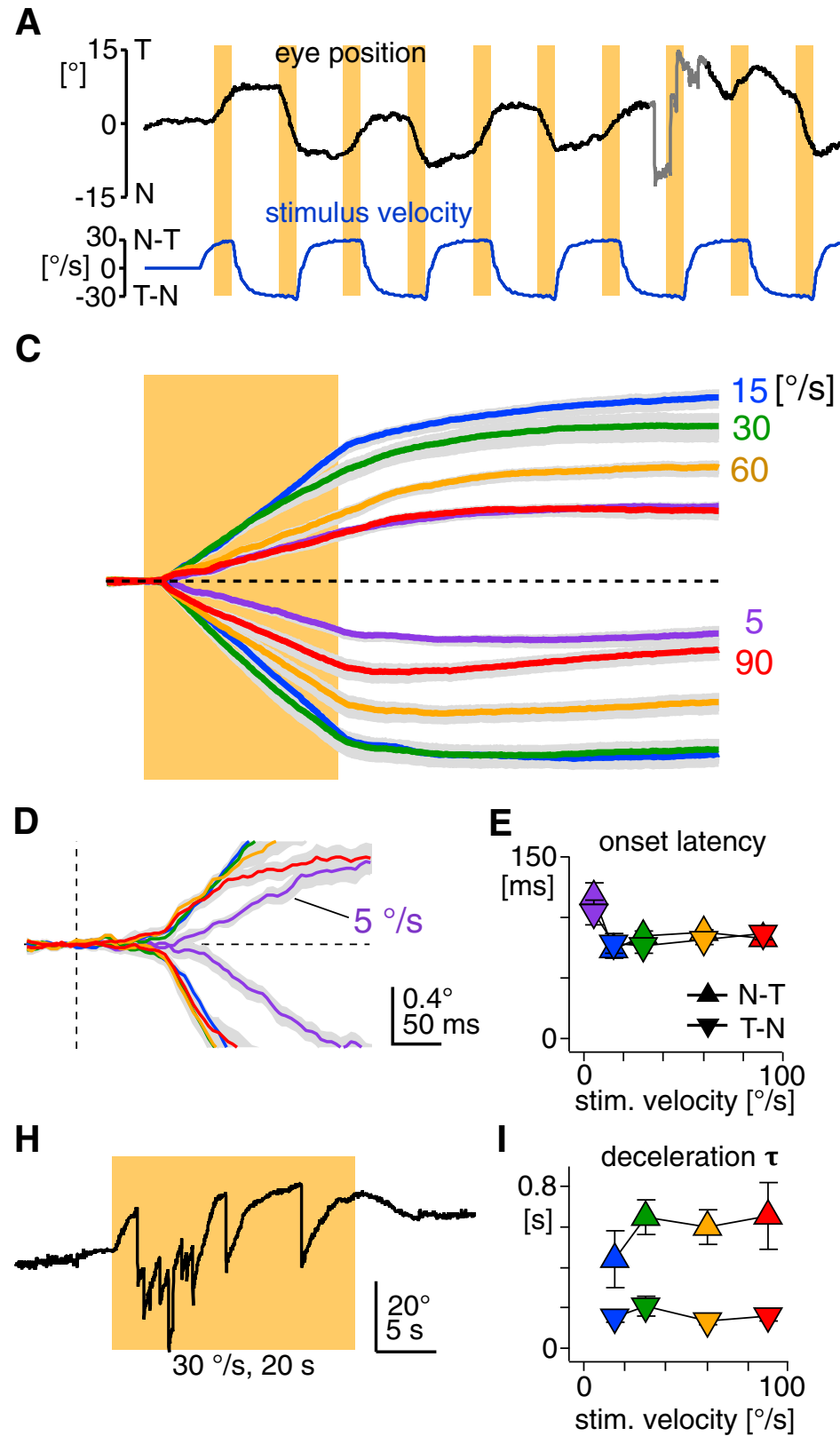

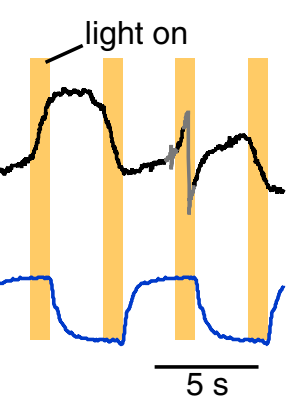

B average eye position

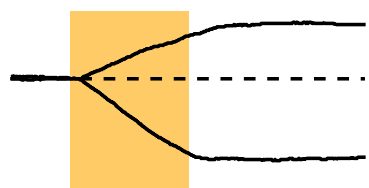

average eye velocity
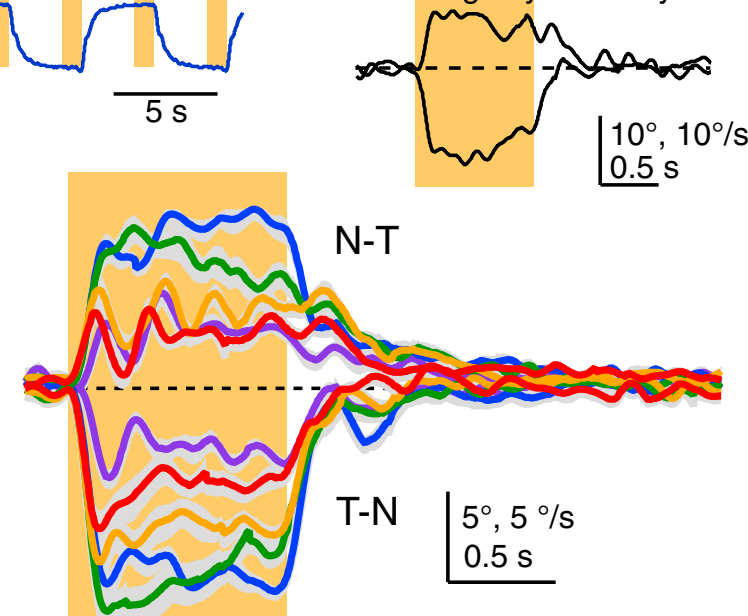

$\mathbf{F}$

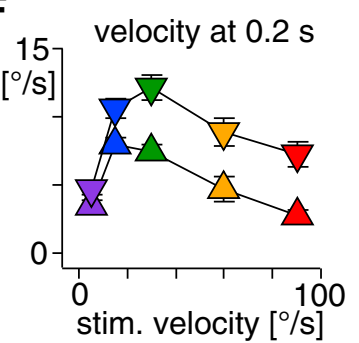

G
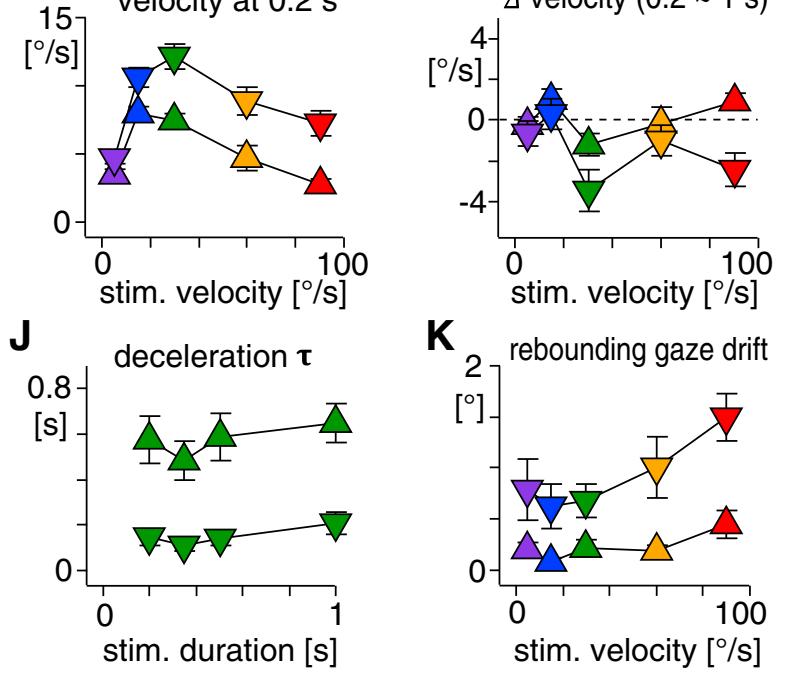

K

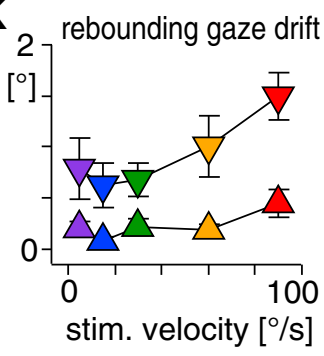

Figure 1. Kinematic features in mouse OKR evoked by $1 \mathrm{~s}$ constant-velocity stimulation. $A$, A part of a raw eye-position trace (top black trace). The mouse was kept in the dark, and visual stimuli were presented by illuminating an optokinetic drum for $1 \mathrm{~s}$ (vertical yellow bars). The drum rotated at a constant velocity $(30 \% \mathrm{~s})$, with alternate changes in direction (bottom blue trace). Gray parts in the eye-position trace contain saccades and erroneous eye-tracking periods (see Material and Methods) that were excluded from the average position and velocity traces shown in $\boldsymbol{B}$. Positive and negative values in eye position correspond to temporal ( $\mathrm{T}$ ) and nasal (N) eye position, respectively. Eye position of $0^{\circ}$ is resting eye position. Positive and negative values in velocity correspond to movements toward the $\mathrm{N}-\mathrm{T}$ and $\mathrm{T}-\mathrm{N}$ directions, respectively. All the position and velocity traces in this paper follow this convention. Visual stimuli were binocularly presented in all the experiments in this paper. $\boldsymbol{B}$, Average eye-position and eye-velocity traces from the data shown in $\boldsymbol{A}$. The yellow bar indicates the visual stimulation ( $\left.\pm 30^{\circ} / \mathrm{s}\right)$. $\boldsymbol{C}$, Average of average eye-position (left) and eye-velocity traces (right) from seven animals. Different line colors indicate stimulation velocities (purple, $5 \% \mathrm{~s}$; blue, $15 \% \mathrm{~s}$; green, 30 $/ \mathrm{s}$; yellow, $60 \% \mathrm{~s}$; red, $90 \% \mathrm{~s}$ ), which are also shown as numbers to the right of the eye-position traces. Dotted lines indicate zero line. Gray envelop of each trace is SEM. D, Close-up of the OKR onset in the average eye-position trace shown in $\boldsymbol{C}$, indicating slower onset at stimulation of $5 \%$ s. $\boldsymbol{E}-\boldsymbol{G}, \boldsymbol{I}-\boldsymbol{K}$, Onset latency $(\boldsymbol{E})$, eye velocity $0.2 \mathrm{~s}$ after the stimulation onset $(\boldsymbol{F})$, eye-velocity change from 0.2 to $1 \mathrm{~s}$ after the stimulation onset $(\boldsymbol{G})$, deceleration $\tau(\boldsymbol{I}, \boldsymbol{J})$, and rebounding gaze drift $(\boldsymbol{K})$ are plotted as a function of stimulation velocity (all but $J$ ) or stimulation duration $(\boldsymbol{J})$. Triangles and inverted triangles indicate measurements from the $\mathrm{N}-\mathrm{T}$ and $\mathrm{T}-\mathrm{N}$ OKRs, respectively. The colors of the symbols correspond to stimulation velocities as in $\boldsymbol{C}$. $\boldsymbol{H}$, Eye-position trace showing the OKR (optokinetic nystagmus) evoked by a prolonged constant-velocity stimulation $(30 \% \mathrm{~s}$ for $20 \mathrm{~s})$. The nystagmus almost ceased in the last half of the stimulation. Error bars, SEM.

neously decreased (i.e., deceleration). Regression to a single exponential function yielded time constants of the eye deceleration (deceleration $\tau$ ), which were consistently larger for the $\mathrm{N}-\mathrm{T}$ than $\mathrm{T}-\mathrm{N}$ OKRs at all the stimulation velocities tested $(15-90 \% \mathrm{~s}: \mathrm{N}-\mathrm{T}$ OKR, $0.59 \pm 0.06 \mathrm{~s}$; T-N OKR, $0.16 \pm 0.02 \mathrm{~s}, n=7$ mice, $p<$ 0.001 ; Fig. $1 I$ ), and almost constant even when the duration of the stimulation was shorter, at least down to $200 \mathrm{~ms}$ (Fig. 1J). Decel- eration $\tau$ in mice was so much smaller than in other species (e.g., $>5 \mathrm{~s}$; in rabbits: Collewijn et al., 1980; monkeys: Cohen et al., 1977; and humans: Fletcher et al., 1990) that we never observed optokinetic after-nystagmus. Deceleration $\tau$ was not measured for the OKRs evoked by the stimulation of $<200 \mathrm{~ms}$ because their velocity always peaked after the end of the stimulation $(50 \mathrm{~ms}$ : $146.3 \pm 30.6 \mathrm{~ms}$ for the N-T OKR, $145.0 \pm 26.5 \mathrm{~ms}$ for the $\mathrm{T}-\mathrm{N}$ 
OKR; $100 \mathrm{~ms}: 136.9 \pm 6.2 \mathrm{~ms}$ for the $\mathrm{N}-\mathrm{T}$ OKR, $173.8 \pm 34.1 \mathrm{~ms}$ for the T-N OKR, $n=8$ mice).

After eye deceleration at stimulus offset, the eye position was maintained at an eccentric position even in the dark (Fig. $1 B, C)$, demonstrating excellent gazeholding capability of mice. However, at higher stimulation velocity, the OKR was followed by a slight eye-position drift toward the direction opposite to the OKR (herein referred to as rebounding gaze drift), which was more evident after the T-N OKR (Fig. $1 K$ ).

Together, the constant velocity stimulation for $1 \mathrm{~s}$ revealed five features in the OKR kinematics of mice: onset latency, acceleration at stimulus onset, imperfect velocity buildup during the stimulation, rapid deceleration at stimulus offset, and steady gaze-holding. The velocity buildup and deceleration are presumed to reflect a neural mechanism, so-called "velocity storage," by which visual and vestibular signals compensate for each other and cooperatively drive proper ocular responses during and after prolonged head rotation in the light (Raphan et al., 1979). Our results confirmed that velocity storage is poorly developed in the oculomotor system of mice (van Alphen et al., 2001; Stahl, 2004).

The performance of the OKR is limited by eye-acceleration capability

The physiological function of the OKR is to suppress image slip on the retina (retinal slip) for visual acuity, and OKR performance is tuned for slow and lowfrequency retinal slip. In response to sinusoidally moving visual stimuli, which is relatively more naturalistic than brief constant-velocity stimuli, the best performance (i.e., highest gain and smallest phase lag) was attained at the stimulation of the lowest velocity and frequency (0.1 $\mathrm{Hz} \pm 3.1 \%$; Fig. 2C,D, pre). OKR performance (gain and phase lag) deteriorated when either velocity or frequency of the stimulation increased, indicating that the sinusoidal OKR operates with limited acceleration capability. Note that, because of the continuity and alternating direction of the stimuli and movements, eye acceleration in the sinusoidal OKR is not equivalent to the one measured using the constant-velocity stimuli, although the latter constrains the former, as described later. From sinusoidal regression of the eye-velocity traces, we analytically estimated modulation amplitude of eye acceleration in the sinusoidal OKR. As stimulus acceleration increased, eye acceleration also increased but saturated at $34.3 \pm 3.7^{\circ} / \mathrm{s}^{2}(n=7$ mice, estimated by single exponential fitting; Fig. $2 E$, pre). The dynamic range of the eye acceleration (measured as $\tau$ of the fitted exponential function,

B

c
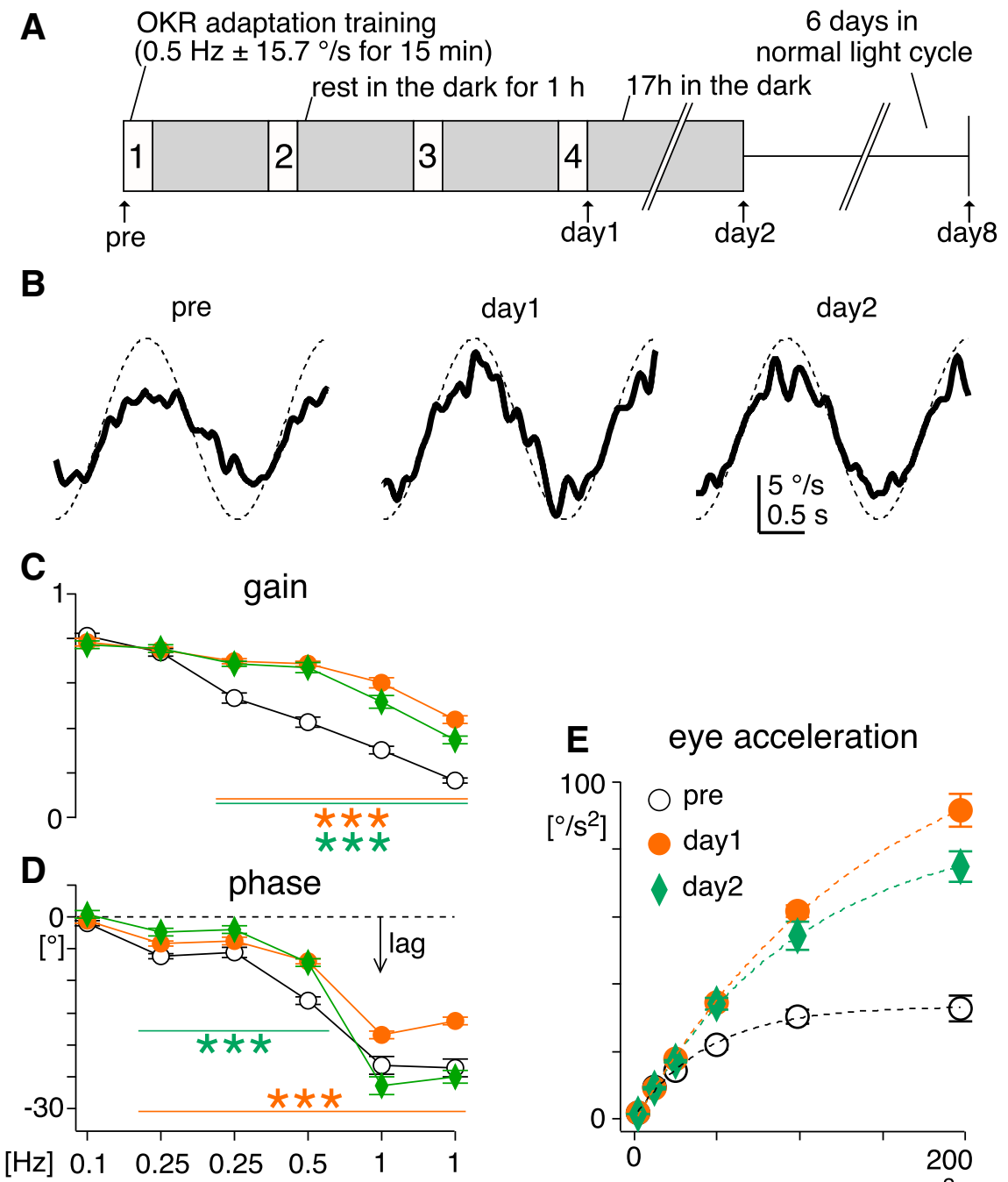

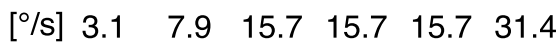

$\left[{ }^{\circ} / \mathrm{s}^{2}\right] 2.0 \quad 12.3 \quad 24.6 \quad 49.3 \quad 96.6 \quad 197.2$

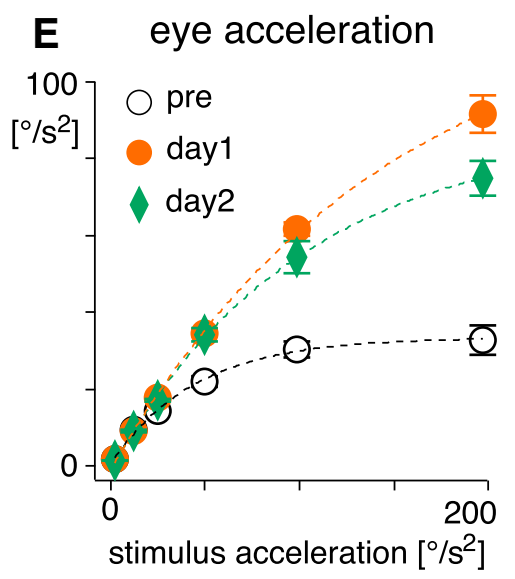

Figure 2. Changes in sinusoidal OKR after OKR adaptation training. $\boldsymbol{A}, 0 \mathrm{KR}$ adaptation training paradigm, comprising four 15 min training sessions where sinusoidal visual stimulation $\left(0.5 \mathrm{~Hz} \pm 15.7^{\circ} / \mathrm{s}\right)$ was presented. After the pretraining recording (pre), mice were placed in a transparent cage at the center of an optokinetic drum, and subjected to the training stimulation with freely moving. Between the training sessions, mice rested for $1 \mathrm{~h}$ in their home cages in the dark (gray filled boxes). After the fourth training session, the OKR was examined (day 1). Then mice were returned to the home cages in the dark for $\sim 17 \mathrm{~h}$ until the recording in the following day (day 2). Subsequently, mice were returned to the normal light cycle, and recovery from the adaptation was tested $6 \mathrm{~d}$ after the day 2 recording (day 8). $\boldsymbol{B}$, Average eye-velocity traces of the $0 \mathrm{KR}$ evoked by sinusoidal stimulation of $0.5 \mathrm{~Hz} \pm 15.7^{\circ} / \mathrm{s}$ (the same as the training stimulation) from a representative animal. Thick continuous and thin dotted traces are eye and stimulus velocity, respectively. $\boldsymbol{C}, \boldsymbol{D}$, Average gain [eye-velocity amplitude divided by stimulation-velocity amplitude $(\boldsymbol{C})$ ] and phase $(\boldsymbol{D})$ of the OKR plotted against different stimulus conditions before (pre, black open circle), immediately after (day 1, filled orange circle), and $\sim 17 \mathrm{~h}$ after the 0KR adaptation training (day 2, green diamond, $n=7$ mice). Frequency, velocity amplitude, and acceleration amplitude of the stimulation are indicated below the $x$-axis. Negative value of phase means that eye movements lagged behind the stimulation. Statistical significance of the difference between pretraining values (open circle) and values at day 1 (orange filled circle) or day 2 (green diamond) are shown by lines and asterisks of corresponding colors. $\boldsymbol{E}$, Average eye-acceleration amplitude plotted against stimulation-acceleration amplitude. Dotted lines are fitted exponential curves. Error bars, SEM.

meaning stimulus acceleration that attains $63.2 \%$ of the maximal eye acceleration) was $45.7 \pm 6.7^{\circ} / \mathrm{s}^{2}$. These results demonstrate that limited eye-acceleration capability of the sinusoidal OKR precludes effective performance to fast and high-frequency visual stimulation (Collewijn, 1969).

\section{OKR acceleration can be adaptively modified}

The OKR is a highly adaptable behavior. For example, when the vestibular system that stabilizes gaze during fast and high- 


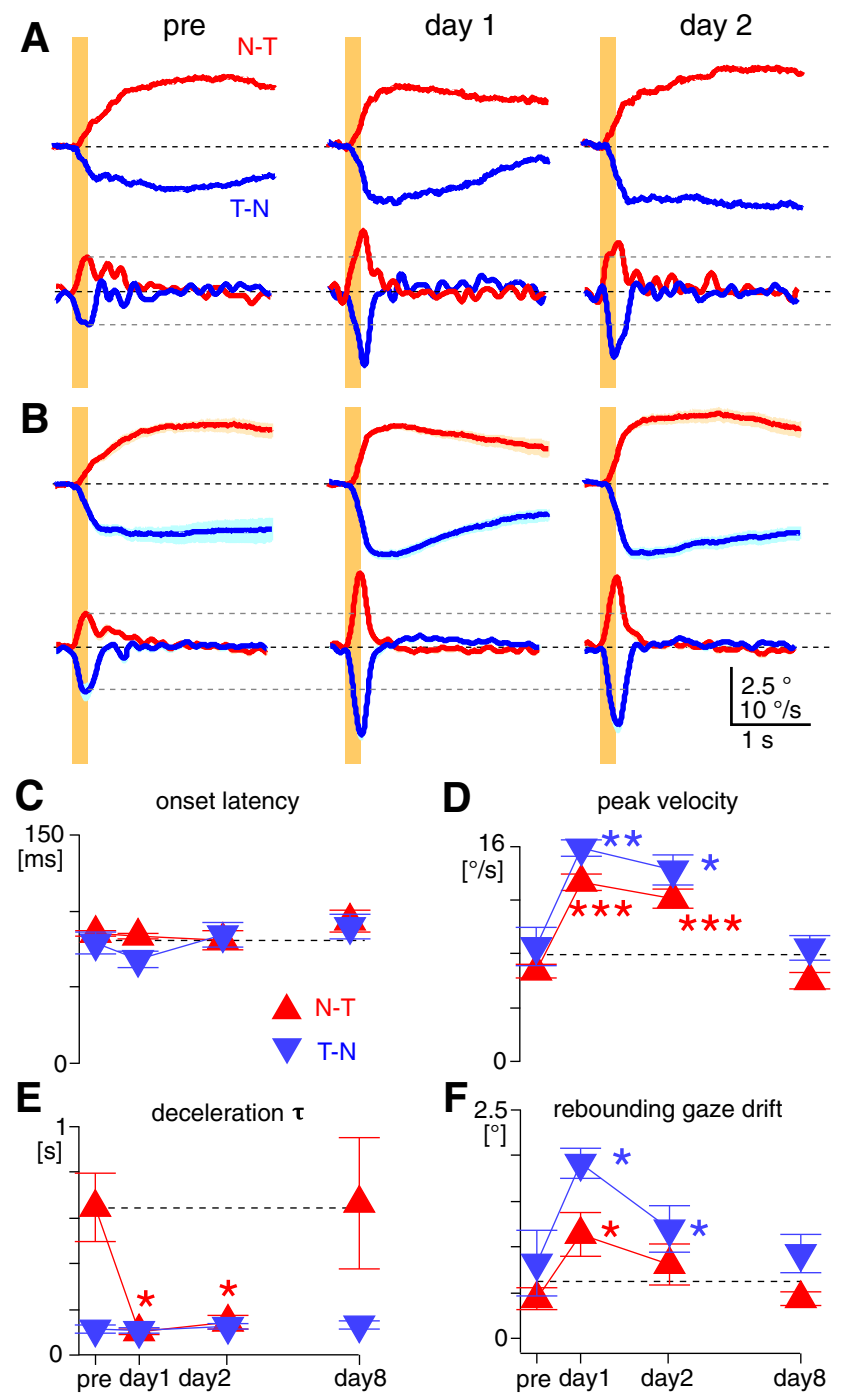

Figure 3. Changes in OKR kinematic features after OKR adaptation training. $\boldsymbol{A}$, Average eyeposition (top) and eye-velocity (bottom) traces of the OKR evoked by constant-velocity stimulation of $30 \%$ for $0.2 \mathrm{~s}$ (yellow bars) from a representative animal. Red and blue traces are the OKRs evoked by stimulation in the N-T and T-N directions, respectively. $\boldsymbol{B}$, Average of average eye-position (top) and eye-velocity (bottom) traces of the 0 KR evoked by the brief constant-velocity stimulation from seven animals trained. Light red or blue shading along the traces are SEM. In $\boldsymbol{A}$ and $\boldsymbol{B}$, horizontal black dotted lines are zero lines. Gray dotted lines are arbitrarily placed to clarify changes of peak velocity after the training. $\boldsymbol{C}-\boldsymbol{F}$, Changes of onset latency $(\boldsymbol{C}$, peak eye velocity $(\boldsymbol{D})$, deceleration $\tau(\boldsymbol{E})$, and rebounding gaze drift $(\boldsymbol{F})$ over the course of the adaptation training. These kinematic features were measured from the OKR evoked by $0.2 \mathrm{~s}$ constant-velocity stimulation at $30 \%$. Red triangles and blue inverted triangles indicate measurements from the $\mathrm{N}-\mathrm{T}$ and $\mathrm{T}-\mathrm{N}$ OKRs, respectively. Statistical significance of the difference from pretraining values are indicated by asterisks in corresponding colors. Horizontal dotted lines are arbitrarily placed to clarify changes from pretraining values. Error bars, SEM.

frequency head movements is impaired, the OKR adaptively enhances its performance to fast and high-frequency visual stimulation, compensating for the vestibular dysfunction (Andreescu et al., 2005; Faulstich et al., 2006). OKR adaptation can be robustly induced by repeatedly exposing subjects to visual stimulation (Collewijn and Grootendorst, 1979; Nagao, 1983; Marsh and Baker, 1997; Katoh et al., 1998). Mice freely moving in a transparent cage were subjected to sinusoidally modulated visual motion stimuli $\left(0.5 \mathrm{~Hz} \pm 15.7^{\circ} / \mathrm{s}\right)$ for $60 \mathrm{~min}$ in total $(15 \mathrm{~min}$ stimulation $\times 4$, with $1 \mathrm{~h}$ interval in the dark; Okamoto et al., 2011; Aziz et al., 2014; Fig. 2A). This visual stimulation ("training") protocol increased gain and reduced phase lag of the OKR in responses to fast and high-frequency stimulation. These plastic changes largely persisted $17 \mathrm{~h}$ after the training (Fig. $2 B-D$, day 2; $n=7$ mice). The maximal eye acceleration analytically estimated from the sinusoidal OKR was dramatically increased after the training [from $34.3 \pm 3.7$ to $136.6 \pm 17.4^{\circ} / \mathrm{s}^{2}$ immediately after the training (day 1), to $95.7 \pm 9.7^{\circ} / \mathrm{s}^{2}$ at day 2; Fig. 2E]. The dynamic range of eye acceleration expanded almost fourfold, from $45.7 \pm 6.7$ to $165.9 \pm 27.4 \% \mathrm{~s}^{2}$ at day 1 , and to $120.1 \pm$ $20.2 \% \mathrm{~s}^{2}$ at day 2 . This potentiated eye-acceleration capability enables the OKR to compensate more accurately for fast and highfrequency visual stimulation.

Which OKR kinematic features are adaptively modified to potentiate acceleration in the sinusoidal OKR? To monitor changes in the OKR kinematics, we measured the OKR evoked by a brief constant-velocity stimulation $(200 \mathrm{~ms}, 30 \% \mathrm{~s})$ before and after the OKR adaptation training $(n=7$ mice; Fig. $3 A, B)$. This brief stimulation was chosen to minimize long-term changes of the OKR by the stimulation itself. Onset latency of the OKR showed no significant change after the training ( $p=0.67$ for both directions, paired $t$ test; Fig. $3 C$ ). In contrast, peak eye velocity almost doubled immediately after the training in both the $\mathrm{N}-\mathrm{T}$ (from $6.7 \pm 0.5$ to $13.3 \pm 0.6 \%$ ) and T-N OKRs (from $8.6 \pm 1.5$ to $15.9 \pm 0.6^{\circ}$ s; Fig. $3 D$ ), and this increase largely persisted until day $2\left(\mathrm{~N}-\mathrm{T}\right.$ OKR, $12.1 \pm 0.7^{\circ} / \mathrm{s} ; \mathrm{T}-\mathrm{N}$ OKR, $\left.14.3 \pm 1.1^{\circ} / \mathrm{s}\right)$, indicating sustained potentiation of eye acceleration at stimulus onset. The peak timing of eye velocity did not change after the training (at day 1: N-T OKR, from $189.3 \pm 16.6$ to $187.1 \pm 7.1$ $\mathrm{ms}$; T-N OKR, from $205.0 \pm 21.1$ to $200.0 \pm 8.2 \mathrm{~ms}, p=0.91$ ). After the training, deceleration $\tau$ persistently decreased in the $\mathrm{N}-\mathrm{T}$ OKR (from $0.65 \pm 0.15$ to $0.10 \pm 0.01 \mathrm{~s}$ at day 1 , to $0.15 \pm$ $0.03 \mathrm{~s}$ at day $2, p<0.05$ ), but not in the T-N OKR (from $0.12 \pm 0.02$ to $0.11 \pm 0.01$ at day 1 , to $0.13 \pm 0.01$ at day $2, p=$ 0.83 ; Fig. $3 E$ ). Intriguingly, the eye velocity decreased beyond zero in both the $\mathrm{N}-\mathrm{T}$ and $\mathrm{T}-\mathrm{N}$ OKRs, reversing the direction of the eye movement (Fig. $3 A, B$ ). In other words, after the training, the OKR was followed not by steady gaze-holding at an eccentric position, but by a marked rebounding gaze drift toward the direction opposite that of the OKR (for both the $\mathrm{N}-\mathrm{T}$ and $\mathrm{T}-\mathrm{N}$ OKRs, $p<0.05$ in paired $t$ test; Fig. $3 F)$. The rebounding gaze drift following the $\mathrm{T}-\mathrm{N}$ OKR $\left(1.9 \pm 0.2^{\circ}\right)$ was greater than the one following the $\mathrm{N}-\mathrm{T}$ OKR $\left(1.1 \pm 0.2^{\circ}\right)$, which reduced but significantly persisted until day 2 (1.2 \pm $\left.0.2^{\circ}, p<0.05\right)$. All of the training effects were extinguished in $6 \mathrm{~d}$ when mice were returned to the normal light cycle (i.e., vision was allowed; Fig. 3D-F).

Overall, the OKR adaptation training persistently facilitated eye acceleration in both the $\mathrm{N}-\mathrm{T}$ and $\mathrm{T}-\mathrm{N}$ OKRs, and deceleration selectively in $\mathrm{N}-\mathrm{T}$ OKRs, accounting for the greater net eye acceleration in the sinusoidal OKR after the training. The rebounding gaze drift observed after the training indicates reduction in the low-frequency component of the OKR (i.e., gazeholding), and could also assist the OKR to high-frequency visual stimulation.

\section{The nasotemporal and temporonasal OKRs are independently adaptable}

Kinematic features of the OKR exhibit differences between the $\mathrm{N}-\mathrm{T}$ and $\mathrm{T}-\mathrm{N}$ directions, reflecting distinct premotor pathways driving eye movements in ipsiversive versus contraversive directions. Can the $\mathrm{N}-\mathrm{T}$ and $\mathrm{T}-\mathrm{N}$ OKRs be adapted independently? To address this, mice were trained with the unidirectional visual stimulation of sinusoidally modulated velocity $\left(0.5 \mathrm{~Hz}, 0-31.4^{\circ} / \mathrm{s}, n=8\right.$ mice; Fig. $\left.4 A\right)$. The acceler- 
ation profile of the training stimulation and the training protocol were kept identical to the previous "bidirectional" training experiment (Fig. 2A). Brief visual stimuli $(200 \mathrm{~ms}, 30 \% \mathrm{~s})$ were used to monitor changes in the OKR kinematics (Fig. $4 B, C$ ).

In the OKR in the same direction as the training stimulus ("trained direction"), both eye acceleration (measured by peak eye velocity; Fig. $4 D$ ) and deceleration (measured by deceleration $\tau$; Fig. $4 E$ ) were significantly potentiated. After the training by $\mathrm{T}-\mathrm{N}$ stimulation, deceleration $\tau$ of the T-N OKR slightly but significantly decreased $(0.14 \pm 0.02$ to $0.11 \pm 0.01 \mathrm{~s}$ at day $1, p<0.05)$, indicating that deceleration of the $\mathrm{T}-\mathrm{N}$ OKR is also modifiable, at least transiently. Remarkably, the training by the $\mathrm{N}-\mathrm{T}$ stimulation significantly (but not persistently) increased peak eye velocity in the untrained $\mathrm{T}-\mathrm{N}$ OKR (Fig. $4 D$, left). On the other hand, the training by the $\mathrm{T}-\mathrm{N}$ stimulation significantly slowed deceleration (i.e., deceleration $\tau)$ in the untrained N-T OKR immediately after the training (Fig. $4 E$, right, day 1). These two changes in the OKR in the untrained direction indicate the crosstalk of OKR adaptation from one direction to the other.

Bidirectional adaptation effects of the unidirectional training were the most evident in rebounding gaze drift (Fig. $4 B, C, F$ ). Immediately after the training, regardless of the training direction, the OKR was always followed by a significant rebounding gaze drift, although the drift significantly persisted for $17 \mathrm{~h}$ only in the T-N OKR after the training by $\mathrm{T}-\mathrm{N}$ stimulation. Onset latency of the OKR showed no change over the course of the training (Fig. $4 G$ ).

Together, these results demonstrate that eye acceleration and deceleration in the $\mathrm{N}-\mathrm{T}$ and $\mathrm{T}-\mathrm{N}$ OKRs could be adapted independently, whereas the development of rebounding gaze drift did not respect the direction of training stimulation. The direction-specific crosstalk of the training effects indicates asymmetry between adaptation mechanisms for the $\mathrm{N}-\mathrm{T}$ and T-N OKRs.

\section{Adaptation of distinct OKR kinematic features follows multiple time courses}

To examine the time course of changes in OKR kinematics over the course of adaptation, mice were trained under the head-fixed condition (bidirectional training by stimulation of $0.5 \mathrm{~Hz} \pm$ $15.7^{\circ} / \mathrm{s}$ ), and the OKR was probed with brief visual stimulation $(200 \mathrm{~ms}, 30 \%$ ) after every $15 \mathrm{~min}$ training session, as well as $17 \mathrm{~h}$ after the last training session (Fig. $5 A, B$ ). Trainingevoked changes in peak eye velocity, deceleration $\tau$, and rebounding gaze drift each followed distinct time courses. Peak velocity in the T-N OKR increased faster than in the $\mathrm{N}-\mathrm{T}$ OKR $(p<0.05$; Fig. $5 C)$. After the training, the increase of peak velocity tended to be greater in the $\mathrm{N}-\mathrm{T}$ OKR than in the $\mathrm{T}-\mathrm{N}$ OKR (N-T, $103.7 \pm 18.7 \%$; T-N, $65.7 \pm 21.8 \%)$, although this did not attain statistical significance $(p=0.11)$. Decreases of deceleration $\tau$ in the N-T OKR were completed after the first 15 min training (Fig. 5D). The rebounding gaze drift increased at an almost constant, but different, rate between the $\mathrm{N}-\mathrm{T}$ and T-N OKRs $(p<0.001)$ over the course of the training for both directions (Fig. $5 E$ ). The changes in peak velocity and deceleration $\tau$ persisted for $17 \mathrm{~h}$ after training, whereas the rebounding gaze drift was almost completely abolished, as observed in the training under the free-moving condition (Fig. $3 D-F)$. These distinct time courses suggest that eye acceleration, deceleration, and gaze-holding are differentially modifiable in the OKR circuit, and that adaptation mechanisms are further differentiated between the $\mathrm{N}-\mathrm{T}$ and $\mathrm{T}-\mathrm{N}$ directions.

\section{Unilateral flocculectomy differentially affects the OKR kinematic features}

Premotor nuclei driving the OKR [medial vestibular nucleus (MVN) and nucleus prepositus hypoglossi (NPH)] are directly innervated by PCs in the floccular complex of the cerebellum. What role do floccular complex PCs specifically play in the OKR? To address this question, we unilaterally lesioned the floccular complex (Fig. 6A) and, using brief visual stimuli $(200 \mathrm{~ms}, 30 \%$, $n=8$ mice), examined how the OKR kinematics changed. Although there were considerable variations across animals (Fig. 

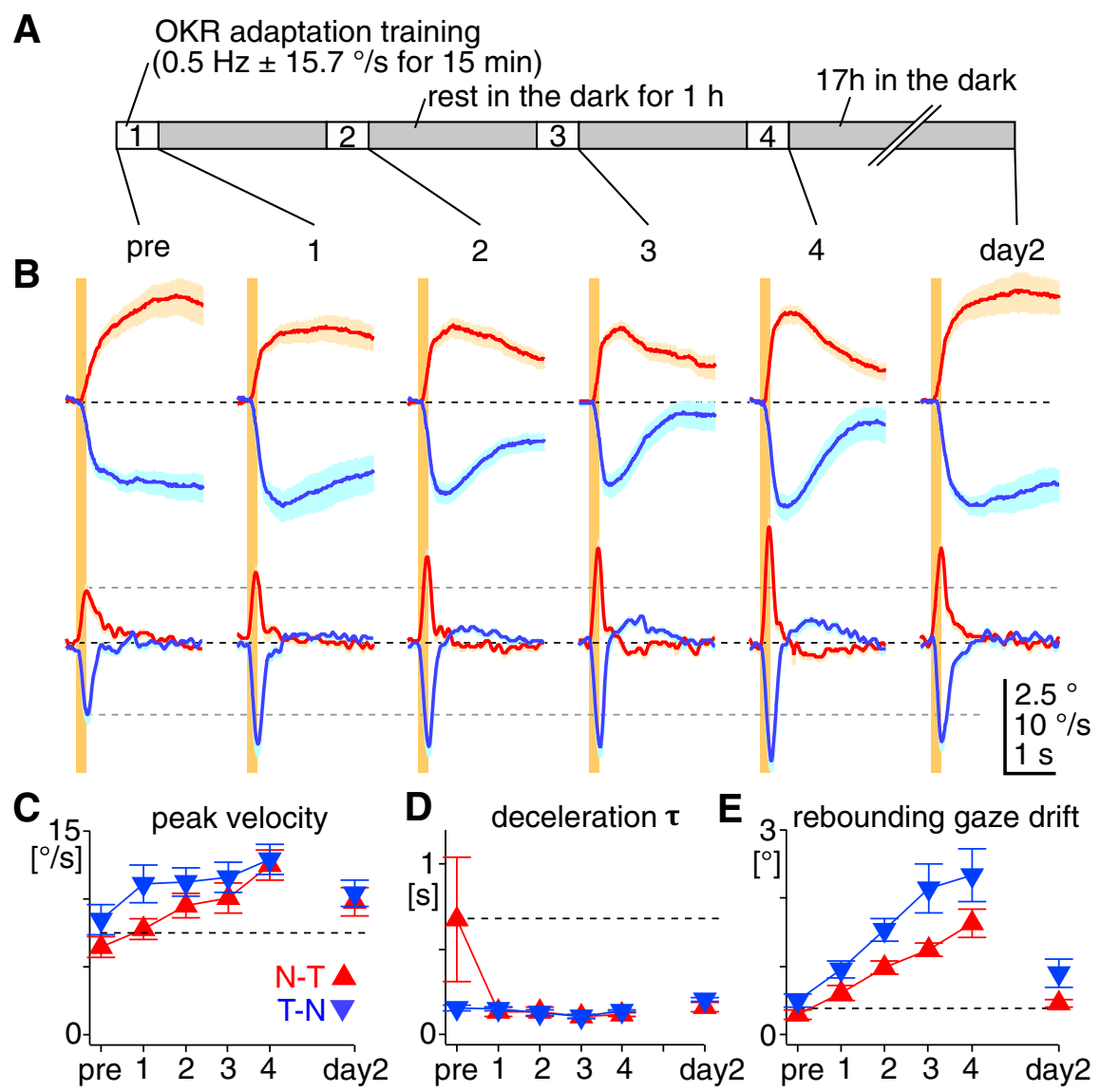

Figure 5. The changes in OKR kinematic features follow distinct time courses during OKR adaptation. A, Schematic illustration of the training and recording schedule. The OKR to $0.2 \mathrm{~s}$ constant-velocity stimulation at $30 \% \mathrm{~s}$ was measured after every $15 \mathrm{~min}$ training session (1-4) as well as before the first training session (pre) and $17 \mathrm{~h}$ after the last training session (day 2). The training was by sinusoidal stimulation of $0.5 \mathrm{~Hz} \pm 15.7^{\circ} \%$ sunder the head-fixed condition. $\boldsymbol{B}$, Average of average eye-position (top) and eye-velocity (bottom) traces of the OKRs evoked by $0.2 \mathrm{~s}$ constant-velocity stimulation $(30 \% \mathrm{~s})$ at different times in the training ( $n=7$ mice). Traces were shown in the same way as in Figure $3 A, B$. $\boldsymbol{C}-\boldsymbol{E}$, Changes of peak eye velocity $(\boldsymbol{C})$, deceleration $\tau(\boldsymbol{D})$, and rebounding gaze drift $(\boldsymbol{E})$ over the course of the adaptation training. These kinematic features were measured from the 0KRs evoked by $0.2 \mathrm{~s}$ constant-velocity stimulation at $30 \%$. Graphs are organized in the same way as Figure $3 C-F$.

$6 C-G$ ), the amplitude of the OKRs (measured as position change at $2 \mathrm{~s}$ after the stimulation) was overall diminished (Fig. 6C), as observed in other species (rabbits: Nagao, 1983; Barmack and Pettorossi, 1985; monkeys: Takemori and Cohen, 1974; Zee et al., 1981; Waespe et al., 1983). The most pronounced change in the OKR kinematic features was in peak eye velocity of the T-N OKR in the eye ipsilateral to the lesioned side, which decreased by $55.3 \pm 7.6 \%(5.4 \pm 0.8 \%$ s, $p<0.01$ in paired $t$ test; Fig. $6 D)$. Peak velocity in the other direction and in the other eye tended to decrease, although this did not attain statistical significance. Deceleration $\tau$ estimated from average velocity traces across animals was reduced in both directions and eyes (i.e., faster deceleration), and this reduction was particularly prominent in the $\mathrm{N}-\mathrm{T}$ OKRs of both eyes (Fig. 6E). Rebounding gaze drift significantly developed in the N-T OKR of the ipsilateral eye and the T-N OKR of the contralateral eye (Fig. $6 F$ ). In other words, the OKR toward the lesioned side was followed by a return of gaze toward the initial position, which may correspond to spontaneous conjugate nystagmus with the slow phase toward the intact side (cats: Courjon et al., 1982; rabbits: Barmack and Pettorossi, 1985) and gaze paretic nystagmus (monkeys: Waespe et al., 1983) observed after unilateral flocculectomy in other species. The lack of nystagmus in mice may be accounted for by poorly developed velocity stor- age, which can temporally integrate erroneous oculomotor commands to drive sustained eye movements, independently from floccular complex function (Zee et al., 1981). Onset latency showed no change (Fig. 6G).

In summary, the $\mathrm{N}-\mathrm{T}$ and $\mathrm{T}-\mathrm{N}$ OKRs in the ipsilateral and contralateral eyes were differentially affected by unilateral flocculectomy, all leading to the diminished OKR. In the ipsilateral eye, faster eye deceleration and rebounding gaze drift conjunctively decreased the N-T OKR, whereas the T-N OKR was poorly initiated (accelerated). In the $\mathrm{N}-\mathrm{T}$ and $\mathrm{T}-\mathrm{N}$ OKRs of the contralateral eye, faster deceleration and rebounding gaze drift primarily account for the smaller OKR, respectively. These results suggest that the floccular complex bilaterally influences all of the mechanisms accounting for the OKR kinematic features (except for onset latency), but to different degree. In particular, acceleration of the T-N OKR predominantly depends on the ipsilateral floccular complex.

\section{Synchronous excitation and inhibition of PCs can accelerate eye movements with high efficacy}

Floccular complex PCs are essential for OKR adaptation (Nagao, 1983; Katoh et al., 1998; Shutoh et al., 2006; Endo et al., 2009; Okamoto et al., 2011; Wada et al., 2014), suggesting that they play a crucial role in eye-acceleration potentiation for OKR adaptation. How effectively can floccular complex PCs accelerate eye movements? To examine eye-acceleration capability of the PCs, we selectively excited and inhibited them using optogenetics and analyzed kinematics of the evoked eye movements. PC-specific expression of channelrhodopsin-2 (ChR2; fused with tdTomato) and ArchT (Han et al., 2011; fused with EGFP) was attained using Pcp2-Cre;Ai27 and Pcp2-Cre;Ai40 lines, respectively. For photoexcitation by $\mathrm{ChR} 2$, stimulation light was delivered through an implanted optical fiber aimed at the PC axonal bundle from the left floccular complex, so that photostimulation could excite as many floccular complex PCs as possible (Fig. 7A). Successful photoexcitation of PCs was confirmed by extracellular recording under ketamine/xylazine anesthesia. In all the PCs encountered in the floccular complex $(n=59)$, photostimulation by continuous light $(0.5 \mathrm{~s})$ instantaneously increased the firing rate (by $124.5 \pm 6.3 \mathrm{~Hz}$ in average firing rate for the entire period of the stimulation; baseline: $34.6 \pm 1.8 \mathrm{~Hz}$; photostimulus: $159.1 \pm 5.8 \mathrm{~Hz}$; Fig. $7 \mathrm{~B}, \mathrm{C}$ ). In some $\mathrm{PCs}$, a transient firing pause, presumably resulting from overexcitation, was observed after photostimulation (Fig. $7 B$ ), although this was not evident in the averaged peristimulus histogram that represented population response of PCs (Fig. 7C).

In awake animals, the $0.5 \mathrm{~s}$ photoexcitation evoked smooth binocular eye movements (Fig. 7D), which were directed toward the side of stimulation (at peak: ipsilateral eye, $11.0 \pm 0.6^{\circ}$ in the $\mathrm{N}-\mathrm{T}$ direction; contralateral eye, $7.8 \pm 0.9^{\circ}$ in the $\mathrm{T}-\mathrm{N}$ direction, $n=12$ animals; Fig. $7 E$ ) as well as downward in the ipsilateral eye 
$\left(6.4 \pm 0.7^{\circ}\right)$ and torsional and upward in the contralateral eye (upward: $3.5 \pm 0.4^{\circ}$; torsional: not measured), as found for electrical stimulation of the floccular PCs in rabbits (Nagao et al., 1985; Van der Steen et al., 1994). In the horizontal movements, eye velocity was instantaneously elevated at stimulus onset in both eyes (peak time: ipsilateral eye, $50.0 \pm 1.6$ $\mathrm{ms}$; contralateral eye, $60.4 \pm 4.9 \mathrm{~ms}$, measured from stimulus onset), but the ipsilateral eye attained higher velocity peak (ipsilateral eye, $39.3 \pm 2.1 \%$ s; contralateral eye, $20.0 \pm 1.9 \%$ s, $p<0.001$ in paired $t$ test), indicating greater acceleration in the ipsilateral eye. During photostimulation, eye velocity declined in the ipsilateral eye, whereas that in the contralateral eye was kept almost constant (Fig. 7E). After photostimulation, the evoked eye movements were followed not by gaze-holding as with the OKR, but instead by a smooth eyeposition drift back to the initial position, which could be fitted by double exponential function (time constants: ipsilateral eye, 0.12 and $0.93 \mathrm{~s}$; contralateral eye, 0.11 and $1.10 \mathrm{~s}$ ). These time constants are slightly larger than those obtained for direct excitation of abducens motor neurons $(<0.05$ and $<0.7$ s; Stahl et al., 2015), suggesting limited recruitment of gaze-holding mechanisms following floccular complex PC excitation. Eye movements could even be evoked by photostimulation of $1 \mathrm{~ms}$, which transiently increases PC firing rate for $\sim 15 \mathrm{~ms}$ (Fig. $7 F, G$ ), effectively adding at most one synchronized spike to the stream of spontaneous PC firing. As shown in Figure $7 \mathrm{H}$, the peak eye position and velocity of the evoked eye movements were larger in the ipsilateral eye $\left(0.57 \pm 0.06^{\circ}, 8.1 \pm\right.$ $\left.1.3^{\circ} / \mathrm{s}, n=10\right)$ than the contralateral eye $\left(0.29 \pm 0.02^{\circ}, 3.5 \pm 0.8^{\circ} / \mathrm{s}, n=6, p<\right.$ 0.05 in unpaired $t$ test). These results demonstrated that synchronized firing of floccular complex PCs can effectively accelerate eye movements, which is greater in N-T-directed movements of the ipsilateral eye.

Photoinhibition of floccular complex PCs also drove eye movements but with distinct kinematics from those by photoexcitation. Because PC axonal photostimulation did not work for photostimulation of ArchT, we instead used somatodendritic photostimulation using thick optical fiber $(910 \mu \mathrm{m}$ in core diameter) subdermally placed toward the floccular complex. The photoinhibition almost completely stopped the firing of all the PCs extracellularly recorded (average firing rate for the entire period of the stimulation: baseline, $25.3 \pm 2.3 \mathrm{~Hz}$; photostimulus, $1.1 \pm 0.7 \mathrm{~Hz}$; Fig. $8 A, B ; n=19$ ). The PC silencing was complete in $<4 \mathrm{~ms}$ after stimulus onset (Fig. $8 B$, bottom
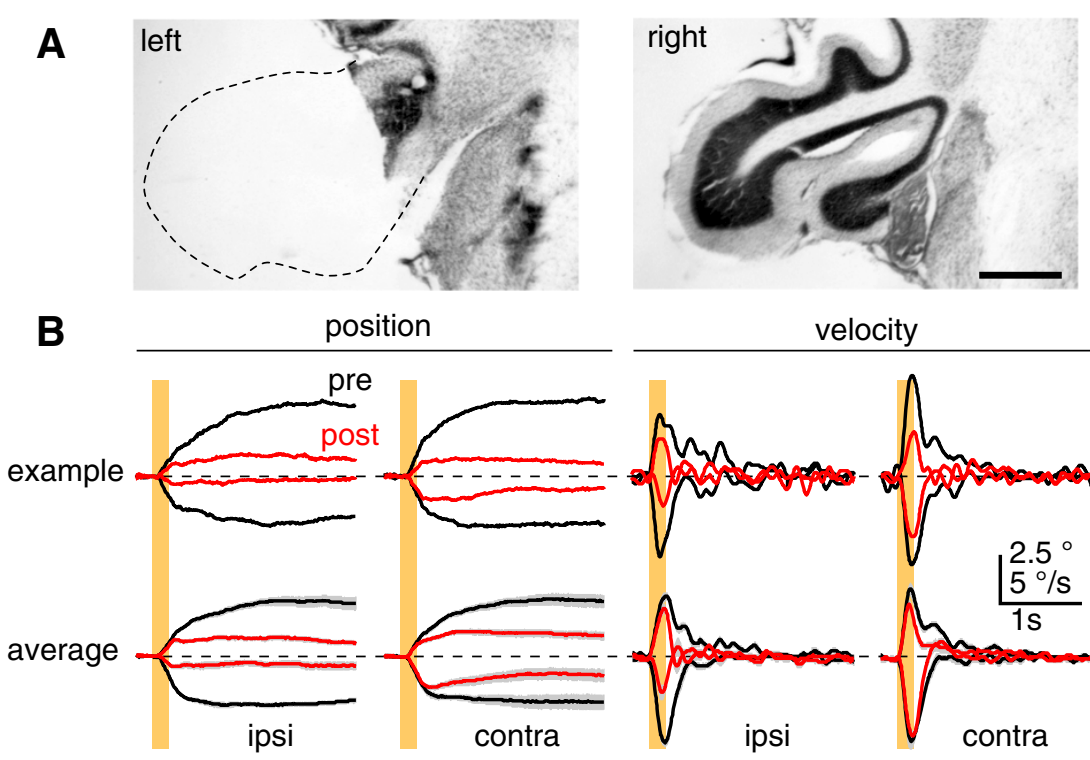

position

velocity

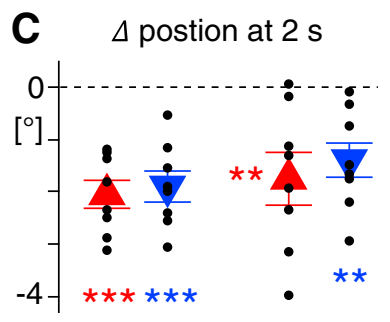

F $\Delta$ rebounding gaze drift
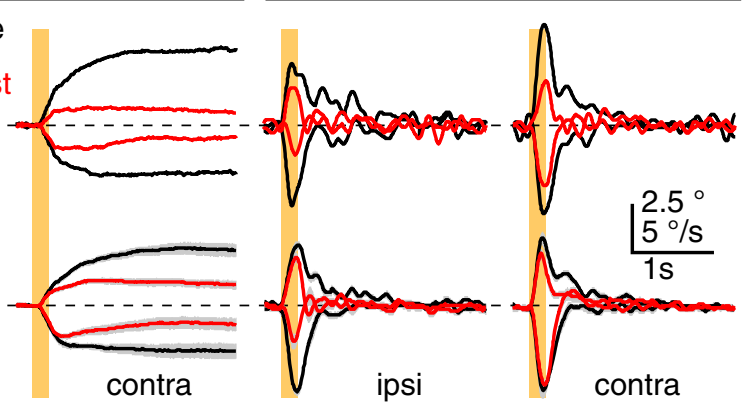

ipsi

contra

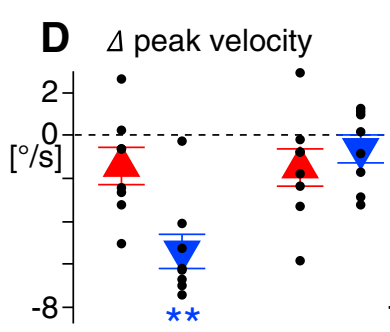

E $\Delta$ deceleration $\mathbf{\tau}$
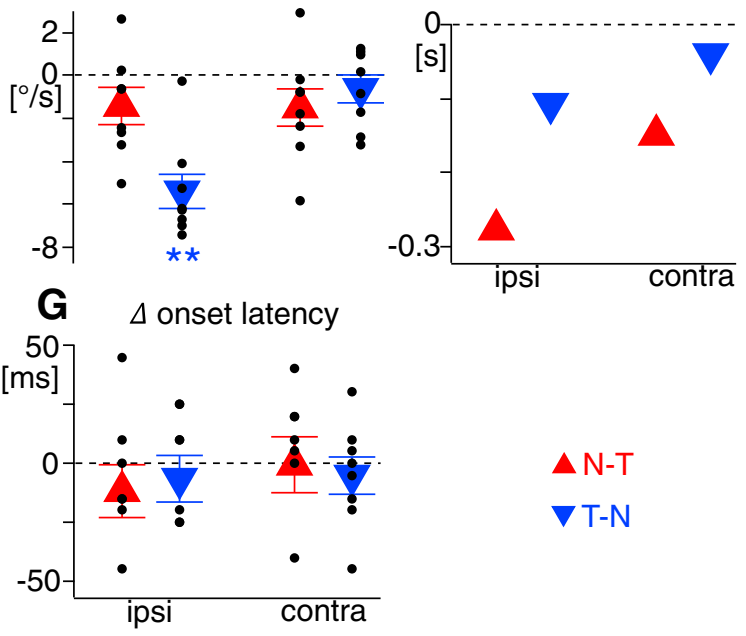

$\Delta \mathrm{N}-\mathrm{T}$

Figure 6. Changes in OKR kinematics after unilateral flocculectomy. $\boldsymbol{A}$, Representative Nissl images of coronal cerebellar sections of lesioned (left) and intact side (right). Dotted line shows contour of presumed location of the lesioned floccular complex. The image of the intact side is horizontally flipped for comparison with the flocculectomized side. Scale bar, $500 \mu \mathrm{m}$. $\boldsymbol{B}$, The OKR right two columns show eye-position and eye-velocity traces, respectively. The sides of recorded eyes are indicated on the bottom. The top row shows average traces from an example mouse. The bottom row is average of average traces from eight flocculectomized mice, where gray shading along the traces are SEM. Yellow bars indicate visual stimulation. $C-G$, Difference of eye position between before and $2 \mathrm{~d}$ after unilateral flocculectomy. Red triangles and blue inverted triangles indicate measurements from the $\mathrm{N}-\mathrm{T}$ and T-N OKRs, respectively. Small black dots indicate measurements from individual animals. Note that deceleration $\tau$ was estimated from average of average velocity traces shown in the bottom row of $\boldsymbol{B}$.

left), indicating that the photoinhibition led to a synchronous firing pause in a substantial population of floccular complex PCs. Following the $0.5 \mathrm{~s}$ photostimulation, PC firing recovered in $\sim 100 \mathrm{~ms}$ (Fig. $8 B$, bottom right). One millisecond light pulses did not evoke significant changes in PC firing $(n=10)$, probably due to slower activation kinetics of ArchT than ChR2 (Han et al., 2011).

The $0.5 \mathrm{~s}$ photoinhibition of floccular complex PCs in awake animals evoked smooth eye movements in directions opposite those evoked by photoexcitation ( $\mathrm{T}-\mathrm{N}$ and upward direction in the ipsilateral eye; Fig. $8 C$; the contralateral eye was not examined). The velocity of the evoked horizontal eye movements ex- 


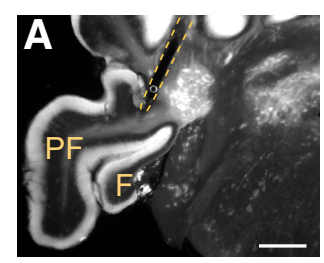

C simple spike rate
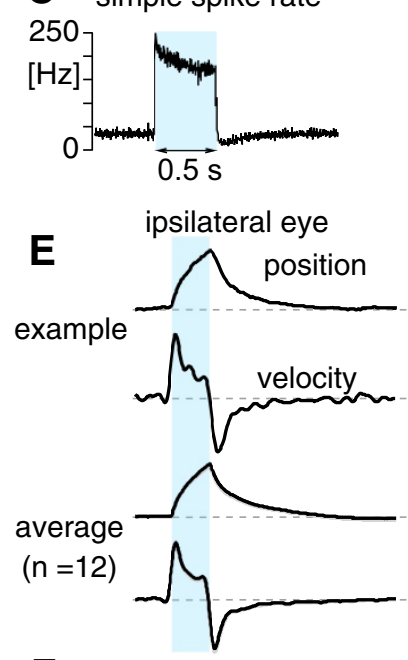

\section{F 1 ms photostim.}

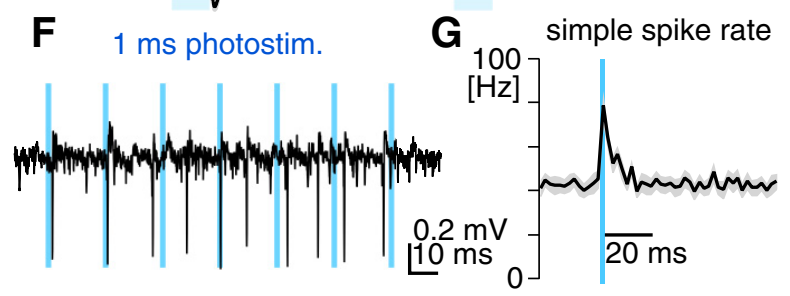

H

D

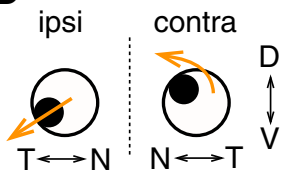

contralateral eye
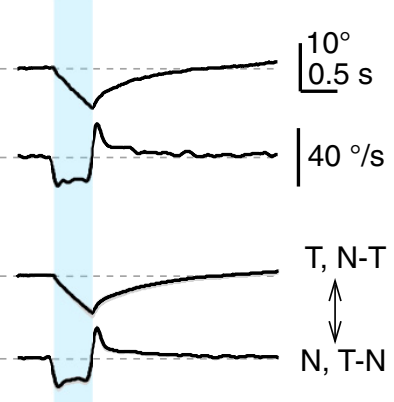
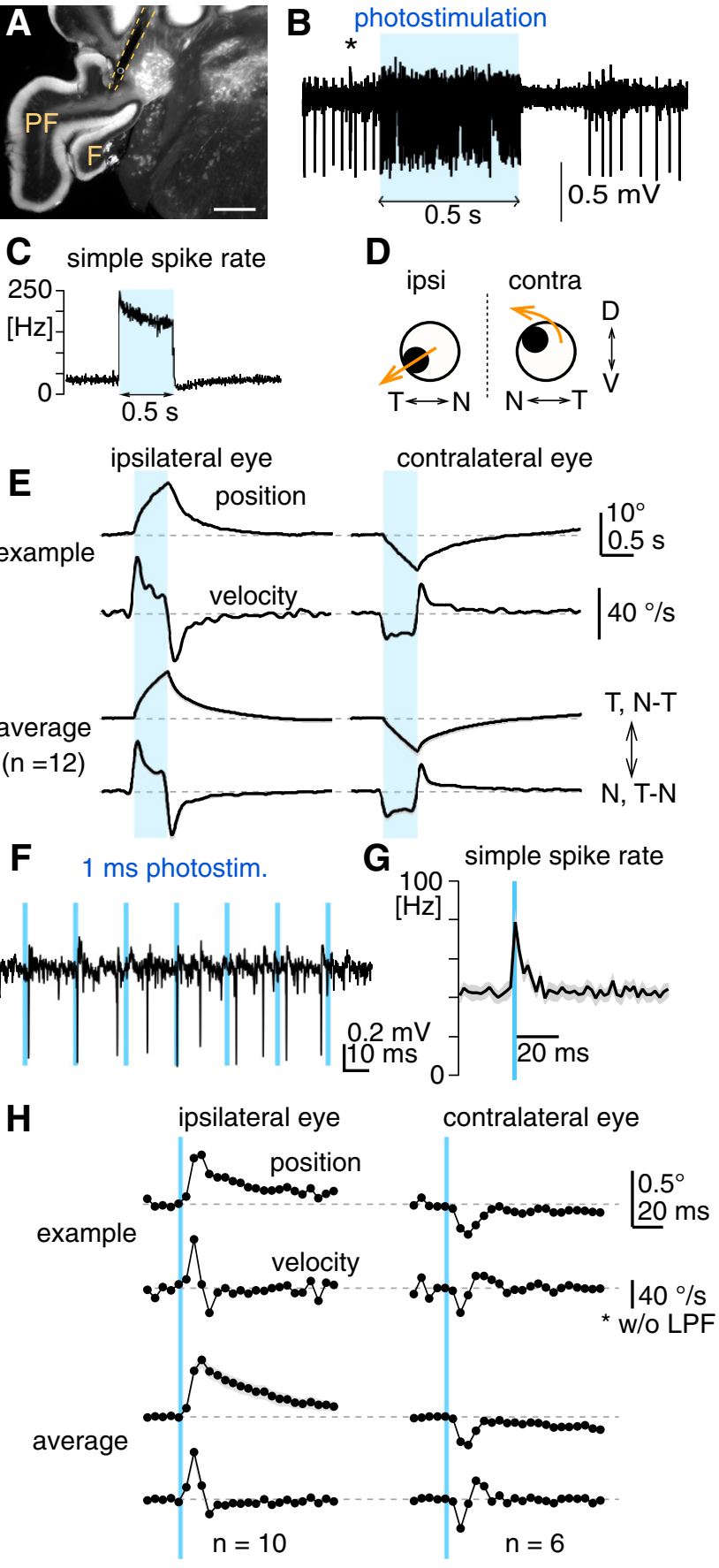

Figure 7. Eye movements evoked by PC-specific excitation using optogenetics. A, Representative fluorescent image of a coronal cerebellar section of an Pcp2-Cre;Ai27 mouse, showing the flocculus (F), paraflocculus (PF), and the track of the implanted optical fiber (dotted yellow line). The tip of the optical fiber was placed on the $\mathrm{PC}$ axonal bundles emerging from the parafloccular region of the floccular complex. Scale bar, $500 \mu \mathrm{m}$. B, An example of extracellular recording of a $P C$ with axonal photostimulation via the implanted optical fiber. A continuous $0.5 \mathrm{~s}$ pulse of blue light (blue rectangle) excited PCs, which was followed by a pause of firing. A complex spike ${ }^{*}$ ) verifies that the recording was from a PC. C, Average peristimulus histogram showing firing rate changes of $\mathrm{PCs}(n=59)$ in response to $0.5 \mathrm{~s}$ light pulse. Bin, $2 \mathrm{~ms}$. D, Schematic summary of eye movements evoked by unilateral photoexcitation of floccular complex PCs. N, Nasal; T, temporal; $D$, dorsal; $V$, ventral. $\boldsymbol{E}$, Horizontal eye movements evoked by unilateral $P($ photoexcitation with $0.5 \mathrm{~s}$ light pulse (blue bars). Left and right columns show movements of the ipsilateral and contralateral eyes, respectively. The top two traces show average eye-position and eye-velocity traces from a representative animal. The bottom two traces are average of average eye-position and eye-velocity traces from 12 animals, where gray shading along traces are SEM. $\boldsymbol{F}$, Extracellular recording of a $\mathrm{PC}$ during photostimulation by a train of $1 \mathrm{~ms}$ light pulses. Each $1 \mathrm{~ms}$ light pulse elicits at most one spike. $\mathbf{G}$, Average peristimulus histogram hibited a peak immediately after stimulus onset $\left(6.5 \pm 1.1^{\circ} / \mathrm{s}\right.$; peak time, $76.0 \pm 15.4 \mathrm{~ms}$ after stimulus onset, $n=5$ animals), which represents eye acceleration by synchronous pause of floccular complex PCs. Eye acceleration evoked by synchronous inhibition of PCs was greater than that of synchronous excitation of PCs with respect to amplitude per given PC firing-rate change (average onset eye velocity for $0.5 \mathrm{~s}$ photostimulation divided by average PC firing rate at corresponding time: 0.27 and $0.18^{\circ} / \mathrm{s} \cdot \mathrm{Hz}$ for photoinhibition and excitation, respectively). The onset eye-velocity peak is followed by a second peak or plateau phase until the end of the stimulus, implying oculomotor commands preferentially driven by prolonged inhibition of floccular complex PCs. Remarkably, at stimulus offset, eye velocity decreased transiently but eye movements outlasted photoevoked inhibition of PC firing until $440.0 \pm 113.3 \mathrm{~ms}$ after the stimulus offset, where eye position peaked at $4.2 \pm 0.6^{\circ}$. Moreover, the decay time course of the eye position was much slower than that by PC photoexcitation (Fig. 8C; time constants from double exponential fitting to the average position trace: 1.85 and $4.17 \mathrm{~s}$ ). These results indicate that the synchronous pause of floccular complex PCs not only accelerates eye movements but also drives gaze-holding mechanisms, as do visual stimuli in the OKR.

Both synchronous excitation and inhibition of floccular complex PCs could effectively accelerate eye movements, whereas PC inhibition selectively activates gaze-holding mechanisms. Because unilateral flocculectomy preferentially impaired acceleration of the T-N OKR in the ipsilateral eye, synchronous PC inhibition driving $\mathrm{T}-\mathrm{N}$ movements is likely to play a predominant role in $\mathrm{T}-\mathrm{N}$ acceleration during the OKR in naive animals, whereas acceleration commands for the N-T OKR would largely originate outside of the floccular complex. OKR adaptation training, however, may enhance synchronization of both excitation and inhibition of the PCs at the onset of visual stimuli through plasticity mechanisms in the cerebellar cortex (Gao et al., 2012), potentiating eye acceleration in the $\mathrm{N}-\mathrm{T}$ and $\mathrm{T}-\mathrm{N}$ direction, respectively.

\section{Discussion}

OKR performance has been thought historically to be limited by the velocity tuning of retinal ganglion cells, which respond best to slowly moving visual stimuli (Oyster et al., 1972). Our findings demonstrate to the contrary that OKR performance in mice can be rapidly and sustainably improved by visuomotor experience, primarily via potentiation of eye acceleration at stimulus onset. Manipulations of cerebellar activity demonstrate that floccular complex PCs are essential and functionally sufficient for eye acceleration and suggest that synchronous modulation of PC firing rates could account for the potentiation of eye acceleration. Differential plasticity in nasotemporal versus temporonasal acceleration and bidirectionally generalized plasticity in gaze-holding after the unidirectional adaptation training imply multiple cerebellar and

$\leftarrow$

showing firing-rate changes of $\mathrm{PCs}(n=25)$ in response to $1 \mathrm{~ms}$ light pulse. Firing rate transiently increases for $\sim 15 \mathrm{~ms}$ after the light pulse, which was not followed by firing inhibition or pause. Bin, $2 \mathrm{~ms}$. $\boldsymbol{H}$, Horizontal eye movements evoked by unilateral PC photoexcitation with 1 ms light pulse (blue lines). The graphs are organized in the same way as in $E$. Average of average eye-position and eye-velocity traces for the ipsilateral and contralateral eyes were made from 10 and 6 mice, respectively. For better temporal resolution of the onset response, eye-velocity traces shown were not low-pass filtered. Note that eye-movement onset timing accuracy is potentially compromised by a transport delay of the video-oculography system (range: 2.05$3.75 \mathrm{~ms})$. 
brainstem sites and mechanisms of experience-dependent adaptation of OKR performance.

\section{Retinal contributions to velocity tuning of the OKR}

Retinal ON-DSGCs are thought to be responsible for the OKR to slow visual stimulation $(\sim 3 \%$ in mice; Dhande et al., 2013), and their responses are severely attenuated with faster stimulation. The maximal eye acceleration of the OKR, however, was attained with stimuli moving at $15-30 \%$ (Fig. 1F; Tabata et al., 2010), which far exceeds the preferred velocity range of ON-DSGCs. How can this discrepancy be explained? One possibility is that the onset response of ON-DSGCs might have a wider velocity preference than a steady-state response. At the onset of visual stimulation, excitatory input onto ON-DSGCs slightly precedes inhibitory input, shaping a short-lasting onset response, which remains discernible even at higher stimulation velocity (Sivyer et al., 2010). Another possibility, which is not mutually exclusive, is that ON-OFF DSGCs contribute to eye acceleration. ON-OFF DSGCs respond to a wider range of stimulation velocities than ON-DSGCs, at least up to $100 \%$ in mice (Weng et al., 2005). Mice lacking functional ON-bipolar cells in the retina can initiate OKR at the onset of visual stimulation (Sugita et al., 2013), suggesting contribution of ON-OFF DSGCs to eye acceleration at stimulus onset. However, the visual cortex, to which a majority of ON-OFF DSGCs send the signal via the lateral geniculate nucleus (Wei and Feller, 2011), is unlikely to contribute to acceleration in the OKR, because lesions of the visual cortex have no influence to the initiation of the OKR in rabbits (Hobbelen and Collewijn, 1971) and rats (Harvey et al., 1997), which have a similar optokinetic system to mice. ON-OFF DSGCs projecting to the nucleus of the optic tract (NOT), which is also a primary projection target of ON-DSGSs (Dhande et al., 2013; Fig. 9), may play a crucial role in OKR acceleration, particularly for visual stimulation of high velocity. By applying the brief visual stimuli used in the present study to mouse lines in which specific DSGCs and their downstream circuits are genetically modified (Sanes and Masland, 2015; Tang et al., 2015), differential contribution of these DSGCs to the OKR would be elucidated.

\section{Mechanisms of eye acceleration in the OKR}

What are the neural circuit substrates of eye acceleration in the OKR? Unilateral flocculectomy revealed that eye acceleration in the T-N OKR largely depends on the ipsilateral floccular complex, indicating that acceleration commands in the T-N direction originate from floccular complex PCs (the only cell type that projects out of the cerebellar cortex). Floccular complex PCs densely innervate somata of inhibitory premotor neurons in the MVN of the same side, which in turn project to the abducens nucleus in the same side (Sekirnjak et al., 2003; Shin et al., 2011). Synchronous pauses in PC firing accelerates T-N movements (Fig. 8), probably via disinhibition of inhibitory premotor neurons in the MVN and consequent inhibition of downstream abducens neurons, which is likely to be a primary motor pathway for T-N OKR acceleration. Synchronous PC pauses are physiologically elicited by synchronous activities of inferior olive (IO) neurons, which innervate PCs via climbing fibers. Impaired temporal coordination of climbing fiber input in connexin 36 knock-out mice may deteriorate eye acceleration, accounting for the delayed turnaround of the OKR when the stimulus direction reverses (Kistler et al., 2002; Van Der Giessen et al., 2008).

In contrast to $\mathrm{T}-\mathrm{N}$ OKR acceleration, $\mathrm{N}-\mathrm{T}$ OKR acceleration was relatively tolerant to unilateral flocculectomy, indicating that acceleration commands in the $\mathrm{N}-\mathrm{T}$ direction originate predominantly outside of the floccular complex. We propose that subcortical visual motion inputs to NPH neurons are critical for N-T acceleration. Figure 9 shows circuits driving the OKR in response to clockwise stimulation in which the left and right eyes move in the T-N and N-T directions, respectively. Clockwise visual stimulation predominantly activates DSGCs in the left retina, which project to the right NOT and dorsal terminal nucleus (DTN) in the pretectum (Dhande et al., 2013). The NOT/DTN relays the visual signal to the premotor nuclei (NPH and MVN) primarily via the precerebellar nuclei [the nucleus reticularis tegmenti pontis (NRTP) and the caudal dorsal cap of the IO] and the floccular complex. Importantly, there is direct excitatory projection from the NOT and NRTP to the NPH in the same side, bypassing the cerebellum (Cazin et al., 1984; Schmidt et al., 1995). This excitatory projection can drive $\mathrm{N}-\mathrm{T}$ OKR acceleration even under flocculectomized condition. The NPH includes neurons that are excited in response to visual stimulation driving the $\mathrm{N}-\mathrm{T}$ OKR in the ipsilateral eye (Lannou et al., 1984), and electrical stimulation of the NPH can drive N-T movements in the ipsilateral eye (Yokota et al., 1992). The NPH plays a crucial role in gazeholding (Mettens et al., 1994; Major et al., 2004), which may account for the difference in rebounding gaze drift between the $\mathrm{N}-\mathrm{T}$ and $\mathrm{T}-\mathrm{N}$ OKRs (Fig. $1 K$ ).

The cerebellum is known to control timing of rapid acceleration/deceleration of movements such as saccades and limb control (Flament and Hore, 1986; Dean, 1995; Takagi et al., 1998; Timmann et al., 2008; Herzfeld et al., 2015), for which rapid modulation of motor neuron firing is necessary. Synchronous firing modulation of PCs may be a general mechanism for the control of movement acceleration. 


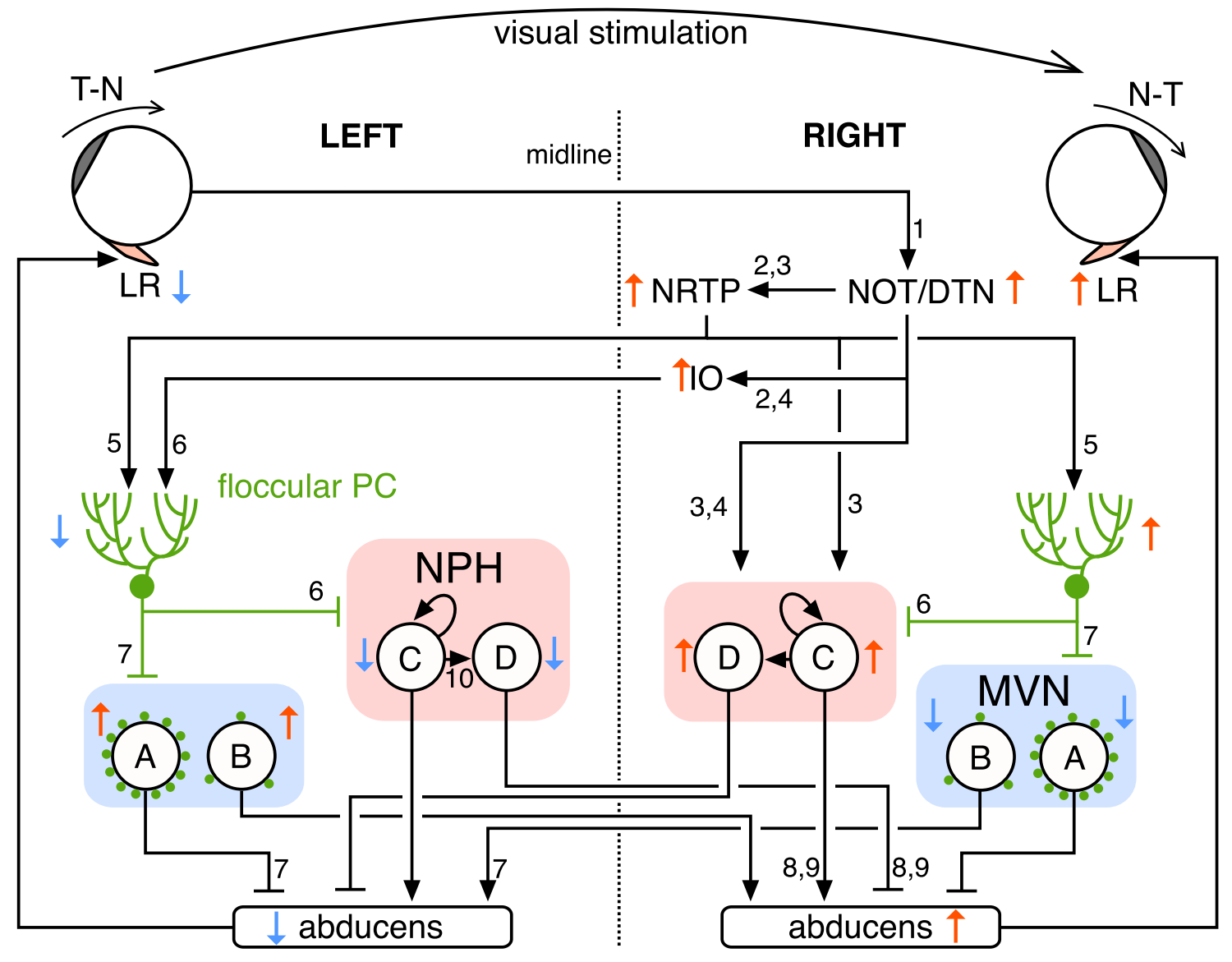

excitatory synapse $\longrightarrow$ inhibitory synapse $\uparrow$ excitation $\quad \downarrow$ inhibition

Figure 9. Summarized OKR circuit from the retina to the lateral rectus. Circled letters in the MVN and NPH indicate neuronal types. $A$, MVN inhibitory premotor neuron. $\boldsymbol{B}$, MVN excitatory premotor neuron. C, NPH excitatory premotor neuron. $\boldsymbol{D}$, NPH inhibitory premotor neuron. Green dots in the MVN indicate degree of floccular complex PC innervation. Looped arrows on NPH excitatory premotor neuron $(\boldsymbol{C})$ express positive feedback through excitatory recurrent network, implementing velocity-position neural integration for gaze-holding. For simplicity, only nuclei and cell types likely to play major roles in the OKR to the clockwise visual stimulation are shown; commissural projections and pathways to the oculomotor nucleus and the medial rectus are omitted. Numbers on lines indicate references anatomically and/or electrophysiologically reporting the projections. Note that references are preferentially selected for mice and the list of references is not comprehensive due to limited space: 1, Dhande et al., 2013; 2, Terasawa et al., 1979; 3, Cazin et al., 1984; 4, Schmidt et al., 1995; 5, Blanks et al., 1983; 6, Schonewille et al., 2006; 7, Shin et al., 2011; 8, Escudero et al., 1992; 9, Lee et al., 2015. LR, lateral rectus; NOT, nucleus of optic tract; DTN, dorsal terminal nucleus; NRTP, nucleus reticularis tegmenti pontis; I0, inferior olive; PC, Purkinje cell; NPH, nucleus prepositus hypoglossi; MVN, medial vestibular nucleus.

\section{Mechanisms of eye acceleration potentiation}

Among the five kinematic features in the OKR, eye acceleration at stimulus onset exhibited the most drastic and persistent changes after OKR adaptation training, largely accounting for the improved OKR performance to fast and high-frequency stimulation. Given the acceleration capability of floccular complex PCs and their necessity for OKR adaptation, it is highly plausible that they are a primary driver of acceleration potentiation. Simple spike rates of floccular complex PCs increase and decrease during the $\mathrm{N}-\mathrm{T}$ and $\mathrm{T}-\mathrm{N}$ OKRs in the ipsilateral eye, respectively (Goossens et al., 2004; Stahl and Thumser, 2014; Katoh et al., 2015), and their modulation during visual motion stimuli is enhanced through OKR training (Nagao, 1988). These reports together with results from the optogenetic PC manipulations reported here (Figs. 7, 8) support the idea that enhanced synchronous excitation and inhibition of floccular complex PCs at visual-stimulus onset account for eye-acceleration potentiation in the $\mathrm{N}-\mathrm{T}$ and $\mathrm{T}-\mathrm{N}$ OKRs, as proposed for saccade adaptation (Herzfeld et al., 2015). Potentiation of T-N OKR acceleration is faster than that of N-T OKRs (Fig. $5 C$ ), perhaps because climbing fiber inputs that drive synchronous PC inhibition can trigger plasticity mechanisms in the cerebellar cortex so effectively that even a single input can lead to behavioral changes (Medina and Lisberger, 2008; Yang and Lisberger, 2014; Khilkevich et al., 2016).

The floccular complex is not the only learning site responsible for OKR adaptation because, once OKR adaptation is fully established through long-term training, induced changes can at least partly persist without intact function of the floccular complex (Shutoh et al., 2006; Okamoto et al., 2011; Wada et al., 2014). We hypothesize that potentiation of excitatory synapses from the NOT/NRTP to the NPH may mediate OKR adaptation in the N-T direction, serving as a "memory locus" downstream of the cerebellum. Given that the NRTP is an origin of mossy fibers projecting to both the floccular complex and the NPH, and that PCs in the floccular complex directly innervate the NPH, the NRTP-NPH synapse might be modified in a PC activity-dependent manner, as reported for 
mossy fiber-to-cerebellar nucleus neuron synapses (Pugh and Raman, 2006; Zhang and Linden, 2006).

An intriguing difference between the $\mathrm{N}-\mathrm{T}$ and $\mathrm{T}-\mathrm{N}$ OKRs is that the training by the $\mathrm{N}-\mathrm{T}$ stimulation alone can transiently potentiate onset acceleration of the T-N OKR (Fig. $4 D$ ). During unidirectional OKR adaptation, PCs in the floccular complex ipsilateral to the eye trained by the $\mathrm{N}-\mathrm{T}$ stimulation (Fig. 9, right) are supposed to be tonically excited (Goossens et al., 2004; Stahl and Thumser, 2014; Katoh et al., 2015), which could plausibly trigger a persistent increase of intrinsic excitability in downstream MVN premotor neurons (Nelson et al., 2003) and thereby facilitate the T-N OKR.

Why is eye acceleration maintained so low in naive animals? The OKR is principally a negative-feedback system, where eye acceleration corresponds to feedback gain. Generally, the low feedback gain is beneficial for stability of the feedback system, and excessively high feedback gain leads to oscillation. In fact, some mice showed small oscillatory eye movements in the light after the OKR adaptation (data not shown), as previously reported with goldfish (Marsh and Baker, 1997). Stability of the OKR might be a driving force by which potentiation of eye acceleration is canceled after the training (Fig. 3D). Regulation of OKR acceleration by the floccular complex is one of the simplest examples of adaptive gain control in sensorimotor feedback systems in which the cerebellum optimizes the balance between movement accuracy and stability.

\section{References}

Andreescu CE, Ruiter MM, De Zeeuw CI, De Jeu MT (2005) Otolith deprivation induces optokinetic compensation. J Neurophysiol 94:3487-3496. CrossRef Medline

Aziz W, Wang W, Kesaf S, Mohamed AA, Fukazawa Y, Shigemoto R (2014) Distinct kinetics of synaptic structural plasticity, memory formation, and memory decay in massed and spaced learning. Proc Natl Acad Sci U S A 111:E194-E202. CrossRef Medline

Barmack NH, Pettorossi VE (1985) Effects of unilateral lesions of the flocculus on optokinetic and vestibuloocular reflexes of the rabbit. J Neurophysiol 53:481-496. Medline

Barski JJ, Dethleffsen K, Meyer M (2000) Cre recombinase expression in cerebellar Purkinje cells. Genesis 28:93-98. CrossRef Medline

Beraneck M, Cullen KE (2007) Activity of vestibular nuclei neurons during vestibular and optokinetic stimulation in the alert mouse. J Neurophysiol 98:1549-1565. CrossRef Medline

Blanks RH, Precht W, Torigoe Y (1983) Afferent projections to the cerebellar flocculus in the pigmented rat demonstrated by retrograde transport of horseradish peroxidase. Exp Brain Res 52:293-306. Medline

Cazin L, Lannou J, Precht W (1984) An electrophysiological study of pathways mediating optokinetic responses to the vestibular nucleus in the rat. Exp Brain Res 54:337-348. Medline

Cohen B, Matsuo V, Raphan T (1977) Quantitative analysis of the velocity characteristics of optokinetic nystagmus and optokinetic afternystagmus. J Physiol 270:321-344. CrossRef Medline

Collewijn H (1969) Optokinetic eye movements in the rabbit: Input-output relations. Vision Res 9:117-132. CrossRef Medline

Collewijn H, Grootendorst AF (1979) Adaptation of optokinetic and vestibulo-ocular reflexes to modified visual input in the rabbit. In: Reflex control of posture and movement (Granit R, Pompeiano O, eds), pp 771-781. Amsterdam: Elsevier.

Collewijn H, Winterson BJ, van der Steen J (1980) Post-rotatory nystagmus and optokinetic after-nystagmus in the rabbit linear rather than exponential decay. Exp Brain Res 40:330-338. CrossRef Medline

Courjon JH, Flandrin JM, Jeannerod M, Schmid R (1982) The role of the flocculus in vestibular compensation after hemilabyrinthectomy. Brain Res 239:251-257. CrossRef Medline

Dean P (1995) Modelling the role of the cerebellar fastigial nuclei in producing accurate saccades: the importance of burst timing. Neuroscience 68:1059-1077. CrossRef Medline
Dhande OS, Estevez ME, Quattrochi LE, El-Danaf RN, Nguyen PL, Berson DM, Huberman AD (2013) Genetic dissection of retinal inputs to brainstem nuclei controlling image stabilization. J Neurosci 33:17797-17813. CrossRef Medline

Endo S, Shutoh F, Dinh TL, Okamoto T, Ikeda T, Suzuki M, Kawahara S, Yanagihara D, Sato Y, Yamada K, Sakamoto T, Kirino Y, Hartell NA, Yamaguchi K, Itohara S, Nairn AC, Greengard P, Nagao S, Ito M (2009) Dual involvement of G-substrate in motor learning revealed by gene deletion. Proc Natl Acad Sci U S A 106:3525-3530. CrossRef Medline

Escudero M, de la Cruz RR, Delgado-García JM (1992) A physiological study of vestibular and prepositus hypoglossi neurones projecting to the abducens nucleus in the alert cat. J Physiol 458:539-560. CrossRef Medline

Faulstich BM, Onori KA, du Lac S (2004) Comparison of plasticity and development of mouse optokinetic and vestibulo-ocular reflexes suggests differential gain control mechanisms. Vision Res 44:3419-3427. CrossRef Medline

Faulstich M, van Alphen AM, Luo C, du Lac S, De Zeeuw CI (2006) Oculomotor plasticity during vestibular compensation does not depend on cerebellar LTD. J Neurophysiol 96:1187-1195. CrossRef Medline

Flament D, Hore J (1986) Movement and electromyographic disorders associated with cerebellar dysmetria. J Neurophysiol 55:1221-1233. Medline

Fletcher WA, Hain TC, Zee DS (1990) Optokinetic nystagmus and afternystagmus in human beings: relationship to nonlinear processing of information about retinal slip. Exp Brain Res 81:46-52. Medline

Gao Z, van Beugen BJ, De Zeeuw CI (2012) Distributed synergistic plasticity and cerebellar learning. Nat Rev Neurosci 13:619-635. CrossRef Medline

Goossens HH, Hoebeek FE, Van Alphen AM, Van Der Steen J, Stahl JS, De Zeeuw CI, Frens MA (2004) Simple spike and complex spike activity of floccular Purkinje cells during the optokinetic reflex in mice lacking cerebellar long-term depression. Eur J Neurosci 19:687-697. CrossRef Medline

Halmagyi GM, Curthoys IS, Cremer PD, Henderson CJ, Todd MJ, Staples MJ, D'Cruz DM (1990) The human horizontal vestibulo-ocular reflex in response to high-acceleration stimulation before and after unilateral vestibular neurectomy. Exp Brain Res 81:479-490. CrossRef Medline

Han X, Chow BY, Zhou H, Klapoetke NC, Chuong A, Rajimehr R, Yang A, Baratta MV, Winkle J, Desimone R, Boyden ES (2011) A high-light sensitivity optical neural silencer: development and application to optogenetic control of nonhuman primate cortex. Front Syst Neurosci 5:18. CrossRef Medline

Harvey RJ, De'Sperati C, Strata P (1997) The early phase of horizontal optokinetic responses in the pigmented rat and the effects of lesions of the visual cortex. Vision Res 37:1615-1625. CrossRef Medline

Herzfeld DJ, Kojima Y, Soetedjo R, Shadmehr R (2015) Encoding of action by the Purkinje cells of the cerebellum. Nature 526:439-442. CrossRef Medline

Hess BJ, Precht W, Reber A, Cazin L (1985) Horizontal optokinetic ocular nystagmus in the pigmented rat. Neuroscience 15:97-107. CrossRef Medline

Hobbelen JF, Collewijn H (1971) Effect of cerebro-cortical and collicular ablations upon the optokinetic reactions in the rabbit. Doc Ophthalmol 30:227-236. CrossRef Medline

Katoh A, Kitazawa H, Itohara S, Nagao S (1998) Dynamic characteristics and adaptability of mouse vestibulo-ocular and optokinetic response eye movements and the role of the flocculo-olivary system revealed by chemical lesions. Proc Natl Acad Sci U S A 95:7705-7710. CrossRef Medline

Katoh A, Shin S-L, Kimpo RR, Rinaldi JM, Raymond JL (2015) Purkinje cell responses during visually and vestibularly driven smooth eye movements in mice. Brain Behav 5:e0310. CrossRef Medline

Khilkevich A, Halverson HE, Canton-Josh JE, Mauk MD (2016) Links between single-trial changes and learning rate in eyelid conditioning. Cerebellum 15:112-121. CrossRef Medline

Kistler WM, de Jeu MT, Elgersma Y, Van Der Giessen RS, Hensbroek R, Luo C, Koekkoek SK, Hoogenraad CC, Hamers FP, Gueldenagel M, Sohl G, Willecke K, De Zeeuw CI (2002) Analysis of Cx36 knockout does not support tenet that olivary gap junctions are required for complex spike synchronization and normal motor performance. Ann N Y Acad Sci 978: 391-404. CrossRef Medline

Lannou J, Cazin L, Precht W, Le Taillanter M (1984) Responses of prepositus hypoglossi neurons to optokinetic and vestibular stimulations in the rat. Brain Res 301:39-45. CrossRef Medline 
Lee MM, Arrenberg AB, Aksay ER (2015) A structural and genotypic scaffold underlying temporal integration. J Neurosci 35:7903-7920. CrossRef Medline

Leigh RJ, Zee DS (2006) The neurology of eye movements. Oxford: Oxford UP.

Madisen L, Mao T, Koch H, Zhuo JM, Berenyi A, Fujisawa S, Hsu YW, Garcia AJ 3rd, Gu X, Zanella S, Kidney J, Gu H, Mao Y, Hooks BM, Boyden ES, Buzsáki G, Ramirez JM, Jones AR, Svoboda K, Han X, et al. (2012) A toolbox of Cre-dependent optogenetic transgenic mice for light-induced activation and silencing. Nat Neurosci 15:793-802. CrossRef Medline

Major G, Baker R, Aksay E, Mensh B, Seung HS, Tank DW (2004) Plasticity and tuning by visual feedback of the stability of a neural integrator. Proc Natl Acad Sci U S A 101:7739-7744. CrossRef Medline

Marsh E, Baker R (1997) Normal and adapted visuooculomotor reflexes in goldfish. J Neurophysiol 77:1099-1118. Medline

Medina JF, Lisberger SG (2008) Links from complex spikes to local plasticity and motor learning in the cerebellum of awake-behaving monkeys. Nat Neurosci 11:1185-1192. CrossRef Medline

Mettens P, Godaux E, Cheron G, Galiana HL (1994) Effect of muscimol microinjections into the prepositus hypoglossi and the medial vestibular nuclei on cat eye movements. J Neurophysiol 72:785-802. Medline

Nagao S (1983) Effects of vestibulocerebellar lesions upon dynamic characteristics and adaptation of vestibulo-ocular and optokinetic responses in pigmented rabbits. Exp Brain Res 53:36-46. Medline

Nagao S (1988) Behavior of floccular Purkinje cells correlated with adaptation of horizontal optokinetic eye movement response in pigmented rabbits. Exp Brain Res 73:489-497. CrossRef Medline

Nagao S, Ito M, Karachot L (1985) Eye field in the cerebellar flocculus of pigmented rabbits determined with local electrical stimulation. Neurosci Res 3:39-51. CrossRef Medline

Nelson AB, Krispel CM, Sekirnjak C, du Lac S (2003) Long-lasting increases in intrinsic excitability triggered by inhibition. Neuron 40:609-620. CrossRef Medline

Okamoto T, Endo S, Shirao T, Nagao S (2011) Role of cerebellar cortical protein synthesis in transfer of memory trace of cerebellum-dependent motor learning. J Neurosci 31:8958-8966. CrossRef Medline

Oyster CW, Takahashi E, Collewijn H (1972) Direction-selective retinal ganglion cells and control of optokinetic nystagmus in the rabbit. Vision Res 12:183-193. CrossRef Medline

Pugh JR, Raman IM (2006) Potentiation of mossy fiber EPSCs in the cerebellar nuclei by NMDA receptor activation followed by postinhibitory rebound current. Neuron 51:113-123. CrossRef Medline

Raphan T, Matsuo V, Cohen B (1979) Velocity storage in the vestibuloocular reflex arc (VOR). Exp Brain Res 35:229-248. Medline

Sanes JR, Masland RH (2015) The types of retinal ganglion cells: current status and implications for neuronal classification. Ann Rev Neurosci 38:221-246. CrossRef Medline

Schiller PH (2010) Parallel information processing channels created in the retina. Proc Natl Acad Sci U S A 107:17087-17094. CrossRef Medline

Schmidt M, Schiff D, Bentivoglio M (1995) Independent efferent populations in the nucleus of the optic tract: an anatomical and physiological study in rat and cat. J Comp Neurol 360:271-285. CrossRef Medline

Schonewille M, Luo C, Ruigrok TJ, Voogd J, Schmolesky MT, Rutteman M, Hoebeek FE, De Jeu MT, De Zeeuw CI (2006) Zonal organization of the mouse flocculus: physiology, input, and output. J Comp Neurol 497:670682. CrossRef Medline

Sekirnjak C, Vissel B, Bollinger J, Faulstich M, du Lac S (2003) Purkinje cell synapses target physiologically unique brainstem neurons. J Neurosci 23: 6392-6398. Medline

Shin M, Moghadam SH, Sekirnjak C, Bagnall MW, Kolkman KE, Jacobs R, Faulstich M, du Lac S (2011) Multiple types of cerebellar target neurons and their circuitry in the vestibulo-ocular reflex. J Neurosci 31:1077610786. CrossRef Medline

Shutoh F, Ohki M, Kitazawa H, Itohara S, Nagao S (2006) Memory trace of motor learning shifts transsynaptically from cerebellar cortex to nuclei for consolidation. Neuroscience 139:767-777. CrossRef Medline

Simpson JI (1984) The accessory optic system. Annu Rev Neurosci 7:13-41. CrossRef Medline

Sivyer B, van Wyk M, Vaney DI, Taylor WR (2010) Synaptic inputs and timing underlying the velocity tuning of direction-selective ganglion cells in rabbit retina. J Physiol 588:3243-3253. CrossRef Medline
Stahl JS (2004) Eye movements of the murine P/Q calcium channel mutant rocker, and the impact of aging. J Neurophysiol 91:2066-2078. CrossRef Medline

Stahl JS, Thumser ZC (2014) Flocculus Purkinje cell signals in mouse Cacnala calcium channel mutants of escalating severity: an investigation of the role of firing irregularity in ataxia. J Neurophysiol 112:2647-2663. CrossRef Medline

Stahl JS, van Alphen AM, De Zeeuw CI (2000) A comparison of video and magnetic search coil recordings of mouse eye movements. J Neurosci Methods 99:101-110. CrossRef Medline

Stahl JS, Thumser ZC, May PJ, Andrade FH, Anderson SR, Dean P (2015) Mechanics of mouse ocular motor plant quantified by optogenetic techniques. J Neurophysiol 114:1455-1467. CrossRef Medline

Sugita Y, Miura K, Araki F, Furukawa T, Kawano K (2013) Contributions of retinal direction-selective ganglion cells to optokinetic responses in mice. Eur J Neurosci 38:2823-2831. CrossRef Medline

Tabata H, Shimizu N, Wada Y, Miura K, Kawano K (2010) Initiation of the optokinetic response (OKR) in mice. J Vis 10(1):13.1-17. CrossRef Medline

Takagi M, Zee DS, Tamargo RJ (1998) Effects of lesions of the oculomotor vermis on eye movements in primate: saccades. J Neurophysiol 80 : 1911-1931. Medline

Takemori S, Cohen B (1974) Loss of visual suppression of vestibular nystagmus after flocculus lesions. Brain Res 72:213-224. CrossRef Medline

Takemura A, Murata Y, Kawano K, Miles FA (2007) Deficits in shortlatency tracking eye movements after chemical lesions in monkey cortical areas MT and MST. J Neurosci 27:529-541. CrossRef Medline

Tang JC, Rudolph S, Dhande OS, Abraira VE, Choi S, Lapan SW, Drew IR, Drokhlyansky E, Huberman AD, Regehr WG, Cepko CL (2015) Cell type-specific manipulation with GFP-dependent Cre recombinase. Nat Neurosci 18:1334-1341. CrossRef Medline

Terasawa K, Otani K, Yamada J (1979) Descending pathways of the nucleus of the optic tract in the rat. Brain Res 173:405-417. CrossRef Medline

Timmann D, Lee P, Watts S, Hore J (2008) Kinematics of arm joint rotations in cerebellar and unskilled subjects associated with the inability to throw fast. Cerebellum 7:366-378. CrossRef Medline

van Alphen AM, Stahl JS, De Zeeuw CI (2001) The dynamic characteristics of the mouse horizontal vestibulo-ocular and optokinetic response. Brain Res 890:296-305. CrossRef Medline

Van Der Giessen RS, Koekkoek SK, van Dorp S, De Gruijl JR, Cupido A, Khosrovani S, Dortland B, Wellershaus K, Degen J, Deuchars J, Fuchs EC, Monyer H, Willecke K, De Jeu MT, De Zeeuw CI (2008) Role of olivary electrical coupling in cerebellar motor learning. Neuron 58:599-612. CrossRef Medline

Van der Steen J, Simpson JI, Tan J (1994) Functional and anatomic organization of three-dimensional eye movements in rabbit cerebellar flocculus. J Neurophysiol 72:31-46. Medline

Wada N, Funabiki K, Nakanishi S (2014) Role of granule-cell transmission in memory trace of cerebellum-dependent optokinetic motor learning. Proc Natl Acad Sci U S A 111:5373-5378. CrossRef Medline

Waespe W, Cohen B, Raphan T (1983) Role of the flocculus and paraflocculus in optokinetic nystagmus and visual-vestibular interactions: effects of lesions. Exp Brain Res 50:9-33. Medline

Wei W, Feller MB (2011) Organization and development of direction-selective circuits in the retina. Trends Neurosci 34:638-645. CrossRef Medline

Weng S, Sun W, He S (2005) Identification of ON-OFF direction-selective ganglion cells in the mouse retina. J Physiol 562:915-923. CrossRef Medline

Yang Y, Lisberger SG (2014) Role of plasticity at different sites across the time course of cerebellar motor learning. J Neurosci 34:7077-7090. CrossRef Medline

Yokota J, Reisine H, Cohen B (1992) Nystagmus induced by electrical stimulation of the vestibular and prepositus hypoglossi nuclei in the monkey: evidence for site of induction of velocity storage. Exp Brain Res 92: 123-138. Medline

Zee DS, Yamazaki A, Butler PH, Gücer G (1981) Effects of ablation of flocculus and paraflocculus of eye movements in primate. J Neurophysiol 46:878-899. Medline

Zhang W, Linden DJ (2006) Long-term depression at the mossy fiberdeep cerebellar nucleus synapse. J Neurosci 26:6935-6944. CrossRef Medline 